$\begin{array}{ll}\text { Variants } & \begin{array}{l}\text { Variants } \\ \text { The Journal of the European Society for Textual } \\ \text { Scholarship }\end{array}\end{array}$

15-16 | 2021

Textual Scholarship in the Twenty-First Century

\title{
The Reconstruction of the Author's Movement Through the Text, or How to Encode Keystroke Logged Writing Processes in TEI-XML
}

\section{Lamyk Bekius}

\section{Q OpenEdition \\ 1 Journals}

\section{Electronic version}

URL: https://journals.openedition.org/variants/1245

DOI: 10.4000/variants. 1245

ISSN: 1879-6095

\section{Publisher}

European Society for Textual Scholarship

\section{Printed version}

Date of publication: 1 July 2021

Number of pages: 3-43

ISSN: 1573-3084

\section{Electronic reference}

Lamyk Bekius, "The Reconstruction of the Author's Movement Through the Text, or How to Encode Keystroke Logged Writing Processes in TEI-XML", Variants [Online], 15-16 | 2021, Online since 01 July 2021, connection on 16 July 2021. URL: http://journals.openedition.org/variants/1245 ; DOI: https:// doi.org/10.4000/variants. 1245 


\title{
The Reconstruction of the Author's Movement Through the Text, or How to Encode Keystroke Logged Writing Processes in TEI-XML
}

Lamyk Bekius

\begin{abstract}
This essay demonstrates how the use of the keystroke logging tool Inputlog allows for a fine-grained analysis of literary writing processes. But before the writing process can be studied, the keystroke logging data needs to be transformed into an output that is suitable for a textual genetic analysis. For this purpose, this essay investigates the potential of combining text with keystroke logging data in TEI-conformant XML. Besides discussing how revisions can be specified in the encoding, the author asks herself how traces of digital writing processes differ from analogue traces (and, taking it one step further, how keystroke logging can be used to record more details about the genesis of a text), what kind of decisions need to be made when encoding keystroke logging data, and how the peculiarities of digital authorship leave their mark on its encoding - as well as on the interpretation and argumentation that underlies the transcription. This will demonstrate that the level of detail that is recorded in keystroke logging data requires us to consider the way in which the text was typed when we design our encoding schemas. The goal of the TEI-XML encoding of the keystroke logging data is to provide transcriptions of writing processes that could be used to analyse (the sequence of) revisions and text production in each logged writing session in relation to their specific location in the text.
\end{abstract}

\section{Introduction}

THIS ESSAY ILLUSTRATES how TEI-XML encoding of keystroke logging data can be used to arrive at a detailed examination of the genesis of present-day literary works that are recorded with a keystroke logger, using the writing processes of the Flemish novelist Gie Bogaert (1958) as a case study. Bogaert divides his writing process into two stages. The first part - the "creative process" as Bogaert calls it - consists of making notes in a paper notebook. Here, he comes up with the concept and structure of the novel, writes character descriptions, and collects additional material. The writing of this notebook must be completed before he can start the second part of the writing process: the "linguistic creative process" 1 This part consists of the actual writing of the novel, for which he

1 This is how Bogaert, in conversation, described his own working method. For a video for the Belgian publishing house Standaard Uitgeverij in which Bogaert describes his creative writing method, see Bogaert 2013 
uses a word processor. As such, Bogaert works both in a "traditional" analogue writing environment, and in a digital one. This way, his working method aptly illustrates the challenges textual scholars and genetic critics face in the (early) twenty-first century. For decades now, geneticists and editors have had methods and tools at hand to study the traces of the writing process in the paper notebook: different colours of ink, interlinear additions, and crossed out words provide valuable clues to gain an insight into the text's genesis. But how do we analyse the genesis of a text that was written in a word processor?

Like Bogaert, most present-day authors predominantly work in a digital environment (Buschenhenke 2016, Kirschenbaum 2016, Kirschenbaum and Reside 2013: Ries 2018: Van Hulle 2014: Vauthier 2016). Common word processors tend to hide the author's writing operations, which makes a detailed reconstruction of the writing process that includes immediate revisions a difficult endeavour (Mathijsen 2009). Without a doubt, as Matthew Kirschenbaum and Doug Reside argue in their essay on "Tracking the Changes", the analysis of these "new textual forms require new work habits, new training, new tools, new practices, and new instincts" (Kirschenbaum and Reside 2013, 272). The consequences of the digital work process for genetic criticism are addressed in the interdisciplinary project Track Changes: Textual Scholarship and the Challenge of Digital Literary Writing that combines aspects of cognitive writing process research with textual scholarship ${ }^{2}$

Within cognitive writing process research, tools have been developed to analyse non-literary writing processes, amongst them what is called keystroke logging: "as an observational tool, keystroke logging offers the opportunity to capture details of the activity of writing, not only for the purpose of the linguistic, textual and cognitive study of writing, but also for broader applications concerning the development of language learning, literacy and language pedagogy" (Miller and Sullivan 2006. 1). With the aim of broadening research coverage from short professional writing processes in educational and corporate contexts to include long-term literary writing processes, the team behind the keystroke logging tool Inputlog (Leijten and Van Waes 2013) at the University of Antwerp collaborated with Bogaert to log the writing process of his tenth novel, Roosevelt (2016). After Bogaert's writing process had been recorded, collaboration was established between the Inputlog team, the Literary Department at Huygens ING (Amsterdam), and the Centre for Manuscript Genetics (University of Antwerp) in order to adequately address the analysis of this literary writing process. This resulted in the interdisciplinary project Track Changes, in which Bogaert's writing process is examined from the perspective of cognitive writing process research, as well as

2 This work has been conducted as part of my $\mathrm{PhD}$ research within the project Track Changes: Textual Scholarship and the Challenge of Digital Literary Writing (2018-2023), a collaboration between Huygens ING (Royal Netherlands Academy of Arts and Sciences, Amsterdam) and the University of Antwerp (Antwerp Centre for Digital Humanities and Literary Criticism) funded by the Dutch Research Council (NWO). Project members include Prof. Karina van Dalen-Oskam, Prof. Dirk Van Hulle, Prof. Luuk Van Waes, Dr Mariëlle Leijten, Vincent Neyt and Floor Buschenhenke. 
from the perspective of genetic criticism. In turn, the collaboration with Bogaert illustrates the possibilities of keystroke logging for genetic criticism in future collaborative projects, or when writers choose to log their writing processes themselves as part of their personal archive ${ }^{3}$

The Inputlog team invited Bogaert to record his writing process with Inputlog. For the purpose of this essay, it is important to keep in mind that this implies that Bogaert's writing process contained a researcher intervention. Throughout the writing process itself, however, this intervention was kept to a minimum: since Inputlog is designed to be as non-intrusive as possible, the further course of the writing process was not influenced (Leijten and Van Waes 2013). Whilst other keystroke logging tools (e.g. Scriptlog, see Wengelin et al.2009) were designed for experimental word-processing environments - and so cannot be used to study writing in a more naturalistic setting - Inputlog logs the data of writing processes that take place in a word processing environment that the author is already familiar with: Microsoft Word (Leijten and Van Waes 2013) 4 Each time an author activates Inputlog to start a new writing session, the Word document in which the author is working is saved in the background, in a folder that contains the session's date and number. Subsequently, the Word document is saved again when the author ends the writing session by de-activating Inputlog. This results in a session-version of the text for each session, which shows the text's gradual expansion. But Inputlog does not just save Word documents. When the program is running, every keystroke and mouse movement is recorded with a timestamp (Leijten and Van Waes 2013). While writing, authors retain control of the process: they can start and stop the logging when they choose, and the data is stored on their local PC or laptop.

Although Inputlog is developed for textual and cognitive study of writing, the data output from the writing process of Bogaert's Roosevelt, generated in Inputlog, is not immediately suitable for literary textual research. While Inputlog provides a video replay of the recorded writing session, some issues emerge when replaying Bogaert's writing process. Short writing sessions comprising linear text production are replayed accurately, but as soon as larger segments of text are relocated or deleted, when the writing is characterized with nonlinearity, or when the logged session is of considerable length, the replay mode is affected and represents the revisions and text production at the wrong location in the text. Moreover, relying solely on a video replay of the writing session for text genetic analysis also seems undesirable, as one would need to watch a writing session of, say, two hours in its entirety, while constantly pausing to analyse the effect of the revisions. A static reconstruction of the writing session - whether or not in combination with a video replay, as in Dirk Van Hulle's

3 Part of the Track Changes project is the development of a new keystroke logger based on Inputlog, which improves the usability and the convenience for the authors so that it can be used for their own archival practices.

$4 \quad$ For an overview of logging tools, see Van Waes et al. 2011 and Lindgren et al. 
proposal for a "Dynamic Facsimile" in the present issue (Van Hulle 2021) - is favoured to ensure adequate analysis. Hence, in order to be able to study the revisions (contained in the keystroke logging data) in their textual context, the twofold output of Inputlog — the Word document and the keystroke logging data - requires some reassembly ${ }^{5}$

Since TEI-conformant XML is widely used to create a digital form of humanities data - texts, manuscripts, archival documents and so on - I opted to encode the keystroke logging data in TEI-XML to visualize and analyse revisions in their textual context (Burnard 2014). For me, these transcriptions function as a tool to gain more insight into the textual genesis. They could eventually be used for visualizations of the writing process, but a proper discussion of the latter lies outside the scope of this article. In order to reflect on how keystroke logging data can be encoded in TEI-conformant XML, this essay discusses a) the way in which the traces of digital writing processes differ from traces of analogue writing processes (and how keystroke logging can be used to record more details about the genesis of a text); b) which decisions we need to consider when we encode keystroke logging data; c) the way in which the peculiarities of digital writing leave their mark on the encoding; and d) the interpretation and argumentation underlying the transcription. The goal of the TEI-XML encoding of the keystroke logging data is to provide transcriptions of the writing processes that could be used to analyse (the sequence of) the revisions and text production in each logged writing session in their location in the text.

\section{Born-digital literature and genetic criticism}

The digital environment in which present-day literature is composed significantly changes the materiality of the sources available for textual scholarship and genetic criticism. Miriam O'Kane Mara argues that "with digital manuscripts, scholars must investigate the methods that authors use as they save their work

5 Within cognitive writing process research, a method has been developed to study revisions in context: the S-notation (Kollberg 1998). This represents the changes in the text at their location and provides information about the range, order and structure of the revisions (Kollberg and Eklundh 2002 91). This computer-based notation can be generated using the keystroke logging data from Inputlog and is provided within the "analyse" feature of the software. However, the S-notation was initially developed to visualize revisions of short writing processes in experimental settings. As such, it appeared to be unsuitable for the study of longitudinal literary writing processes logged in their natural setting. Literary writing processes may take up several years and hundreds of writing sessions, with the production of an extensive number of words. As a result, the S-notation could not be generated using the keystroke data gathered from Bogaert's writing process. More generally, the S-notation does not allow for further annotation and processing. Another problem concerns the representation of deleted text. Since Inputlog logs the position of the event according to its position on the $\mathrm{x}$ - and $\mathrm{y}$-axes of the MS Word document, the deleted text is not always presented correctly (the only information the keyboard provides about a deletion is usages of the delete or backspace key). This hinders an automatically generated visualization of the revisions in their textual context. 
as well as the software and hardware systems through which they compose" (Mara 2013, 345). Several explorations of the digital literary writing process have already been published since then that explore digital files, file formats, and media types.

In Track Changes. A Literary History of Text Processing (2016), for example, Matthew Kirschenbaum describes the emergence of the word processor and its adoption among Anglo-American authors. And in "The rationale of the born-digital dossier génétique", Thorsten Ries analysed born-digital records from the hard drives of the German poet Thomas Kling (Ries 2018; see also Ries 2017). Ries argues that the digital forensic record of the writing process comprises "digital documents", but also metadata, automatically saved draft snapshots, recoverable temporary files and other fragmented traces scattered across the hard drive (Ries 2018, 417). The use of applications such as a hex editor, a binary parser, an undelete tool, or a file carver can reveal revision and intermediate steps in the writing process (Ries 2018, 418). For example, the socalled "scratch file" [ WRS0003.tmp] with the first paragraph of the first chapter of Kling's essay Herodot (2005) "contains an almost complete protocol of the first writing phase of this paragraph in the form of text additions and textual variants from the first written line on to a point of time between [ WRL3681.tmp] and [ WRA1775.wbk]" - two other temporal and backup files (Ries 2017, 141). After extracting the fragments, Ries could reconstruct the nonlinear development process of this paragraph, with inclusion of editing phases and correction of typing errors (Ries 2017, 142). Still, as Ries mentions, "although the relative, layered sequence of edits can be determined [...] due to textual fragmentation, it is not in all cases possible to determine a consistent text status at any given time with certainty" (Ries 2017, 142). Bénédicte Vauthier took on the task of investigating the digital files the Spanish writer Robert Juan-Cantavella saved during the writing of his novel El Dorado (2008). After comparing digital documents and analysing the tree structure of the folders and other metadata such as the file title and creation date, she concluded that, "although the dossier does not contain the normal traces of writing - cancellations, additions, shifts whose absence [...] would appear to make our analysis practically impossible, collating and comparing the digital documents and files gives us more than a sound basis to allow a meaningful genetic investigation" (Vauthier 2016. 175). Although the research above has proven that the digital writing process can leave sufficient traces to ensure genetic analysis, immediate revision and correction of typing errors remain often - apart from some exceptions - irretrievable.

Most genetic studies of born-digital writing processes work with self-archived born-digital materials received directly from the authors in question (see, for example, Crombez and Cassiers 2017: Vásári 2019: Vauthier 2016). This already indicates how important it is to collaborate with authors for this kind of research. Collaboration between writers, scholars and archivists has already been advocated by Catherine Hobbs with regard to born-digital archives, "to understand the relationship between writers, their documentation and their creative vision" 
(Hobbs, qtd. in Gooding et al. 2019. 384). To be able to study the genesis of a born-digital work of literature in more detail, the collaboration with authors may be extended, for example, by logging their writing process with a keystroke logger. Between 2014 and 2018, the English novelist C. M. Taylor collaborated with the British Library to record the writing process of his novel Staying On (2018) using the keystroke logging software Spector Pro. Taylor, driven by both the "lost drafts" in digital writing and the loneliness of the writing process, contacted the digital curation team of the British Library, and decided together to record the writing process (Taylor 2018 n.p.). As for copyright, they agreed that the recorded data would belong to the British Library, while that of the resulting book would belong to Taylor. On the "English and Drama blog" of the British Library, Taylor quoted Jonathan Pledge (curator of contemporary archives at the British Library) who stated that the used software "seem[ed] to have been specifically designed for low-level company surveillance of employees, potentially without their knowledge" (Taylor 2018 n.p.). This use case scenario becomes apparent in the material that was recorded: the document with the text was not automatically saved after each writing session, although the software did save a screenshot "captured every few seconds each time activity on the host computer is detected", and Taylor saved some intermediate versions himself (Taylor 2018, n.p.). Also, the software did not record the location of the keystroke within the document itself, nor the time of each individual keystroke. This suggests that while the recorded material undeniably contains valuable information about Taylor's writing process, the software that was used seems to make it even more difficult to pursue a detailed reconstruction of the revisions in their textual context than is the case with Inputlog.

Although keystroke loggers originated as spyware, both Inputlog and Script$\log$ (another keystroke logging program) have been developed specifically to observe writing processes for research purposes (Wengelin et al. 2009). The keystroke logging files logged with Scriptlog can be read and processed within the Inputlog environment (Van Hoorenbeeck et al. 2015) 6 As a result, the proposed encoding below could also be applied to writing processes logged with Scriptlog. In addition, if it is possible to represent the revisions made by Taylor - as well as revisions logged with other keystroke loggers - in their textual context, the revision types given below may also be distinguished in this material.

\section{Keystroke logging data and its use for genetic criticism}

So what does Inputlog's recorded keystroke logging material consist of? Bogaert wrote Roosevelt in 266 days - from July 2013 to December 2015 - during which

6 The same applies to eye and handwriting observation software EyeWrite, EyePen and HandSpy (Van Hoorenbeeck et al. 2015). 
447 writing sessions took place, each logged with Inputlog. Of these sessions, 422 were dedicated to the writing of the novel. Luuk Van Waes assisted Bogaert in installing Inputlog, and was available for questions or when problems occurred. The 422 writing sessions resulted in 453 session-versions ${ }^{7}$ showing the gradual expansion of the text, and 277 hours, 14 minutes and 22 seconds of keystroke logging data 8

Let us zoom in on the the composition of a single sentence written by Bogaert in session thirty:

Soms kan hij meer krijgen dan wat hij voor zo'n kunstwerkje vraagt, maar dat wil hij nooit.

[Sometimes he can get more than he asks for such a work of art, but he never wants that. $]^{9}$

All the writing actions performed in composing this sentence are listed in Table 1 Since all the different steps Bogaert took to arrive at this sentence are recorded in Inputlog's General Analysis logs, keystroke logging facilitates an analysis of the text with a granularity that cannot be obtained when working with analogue materials.

In the typology of writing processes of literary works, genetic criticism distinguishes between exogenetic, endogenetic, and epigenetic writing processes - all of which can be studied from a microgenetic point of view, and from a microgenetic one (Biasi 1996: Van Hulle 2016). "Microgenesis" here includes all intra-textual processes: "the processing of a particular exogenetic source text; the revision history of one specific textual instance across endogenetic and/or epigenetic versions; the 'réécritures' or revisions within one single version" (Van Hulle 2016, 50). The "macrogenesis" on the other hand, embodies "the genesis of the work in its entirety across multiple versions" (Van Hulle 2016. 50). When examining keystroke logging data, the geneticist can examine the writing process at an unprecedented level of granularity. The fine-grained data of keystroke logging therefore allows for a new type of what can be called "nanogenetic" research 10

Central to a work's nanogenesis would be the author's movement through the text, as the writing process is taking place. Thanks to keystroke logging software, this highly detailed form of sequentiality can be deduced from logged events that allow us to reconstruct the order in which the text was typed - for

7 In some sessions the initial document did not correspond with the end document from the previous session, so there are more session-versions than sessions.

8 For an example of how the successive events in these sessions were logged, see Table 8 in the Appendix below, which shows a detail from the General Analysis generated by Inputlog. The General Analysis of each writing session represents every event that was recorded during that session.

9 All the translations of Bogaert's sentences are my own. I have tried to stay as close as possible to the original Dutch sentences in my translation.

10 See also Dirk Van Hulle's contribution on "Dynamic Facsimiles" in the present issue of Variants. 
Table 1: Writing actions in the composition of the sentence "Soms kan hij meer krijgen dan wat hij voor zo'n kunstwerkje vraagt, maar dat wil hij nooit."**

\begin{tabular}{|c|c|}
\hline Writing action & Text \\
\hline adds: Soms beiden & Soms beiden \\
\hline adds: krijgt $\mathrm{h}$ & Soms krijgt hbeiden \\
\hline adds kan hij meer & Soms kan hij meer krijgt hbeiden \\
\hline $\begin{array}{l}\text { adds: en dan wat hij voor zon, } \\
\text { kunstwerkje vraagt }\end{array}$ & $\begin{array}{l}\text { Soms kan hij meer krijgen dan wat hij voor } \\
\text { zon' kunstwerkje vraagtt hbeiden }\end{array}$ \\
\hline deletes: $\mathrm{n}$ & $\begin{array}{l}\text { Soms kan hij meer krijgen dan wat hij voor } \\
\text { zo' kunstwerkje vraagtt hbeiden }\end{array}$ \\
\hline adds: $\mathrm{n}$ & $\begin{array}{l}\text { Soms kan hij meer krijgen dan wat hij voor } \\
\text { zo' } n \text { kunstwerkje vraagtt hbeiden }\end{array}$ \\
\hline deletes: $t$ hbeiden & $\begin{array}{l}\text { Soms kan hij meer krijgen dan wat hij voor } \\
\text { zo'n kunstwerkje vraagt }\end{array}$ \\
\hline adds: , maar dat il hij niet & $\begin{array}{l}\text { Soms kan hij meer krijgen dan wat hij voor } \\
\text { zo'n kunstwerkje vraagt, maar dat il hij } \\
\text { niet }\end{array}$ \\
\hline adds: w & $\begin{array}{l}\text { Soms kan hij meer krijgen dan wat hij voor } \\
\text { zo'n kunstwerkje vraagt, maar dat wil hij } \\
\text { niet }\end{array}$ \\
\hline adds: . & $\begin{array}{l}\text { Soms kan hij meer krijgen dan wat hij voor } \\
\text { zo'n kunstwerkje vraagt, maar dat wil hij } \\
\text { niet. }\end{array}$ \\
\hline adds: ooit & $\begin{array}{l}\text { Soms kan hij meer krijgen dan wat hij voor } \\
\text { zo'n kunstwerkje vraagt, maar dat wil hij } \\
\text { nooitiet. }\end{array}$ \\
\hline deletes: iet & $\begin{array}{l}\text { Soms kan hij meer krijgen dan wat hij voor } \\
\text { zo'n kunstwerkje vraagt, maar dat wil hij } \\
\text { nooit. }\end{array}$ \\
\hline
\end{tabular}

example, whether the author left a sentence while composing it — and the way in which words were deleted. This level of detail of movement through a text cannot be deduced from an analogue document in which "the documentary evidence is often so complex that it becomes impossible to determine the order in which these revisions were made with any degree of certainty" (Dillen 2015. 90). The fact that the analysis of keystroke logging data here allows us to succeed exactly where traces of analogue writing processes crucially fall short warrants

These writing actions are deduced from Inputlog's General Analysis logs. A copy of the original logs can be found in Appendix B below. 
the coinage of a new concept such as that of nanogenesis. In addition, it is important to realize that a work's microgenesis and nanogenesis can be studied separately: one could, for example, study the variation of one specific paragraph without taking the fine-grained details about the exact order of the keystrokes into account, or, conversely, solely focus on the author's movement through the text.

In the case of digital documents, Mara claims that "different types of software mould and shape the writing process, making software a collaborator of sorts" (Mara 2013. 344). Although primarily relying on how the Irish writer Nuala O'Faolain describes writing in a word processor in her memoirs, Mara indicates changes in the author's writing process as they move to the digital environment, "a process that differs from traditional drafting and revision" (Mara 2013, 345). For O'Faolain, "the digital environment provides a sense of freedom and lack of fear because so-called mistakes can be easily rectified and revision can be immediate" (Mara 2013, 346). Writing on a laptop computer provided O'Faolain with a freedom and fluidity that "indicates for her a willingness to play with words and structures that other media might not promote" (Mara 2013. 344; emphasis in original). It is exactly this new mode of writing that is recorded with keystroke logging, and could be described by means of nanogenetic research.

The disadvantage of keystroke logging data such as those recorded by Input$\log$, however, is that the processes are recorded in such detail that the logs become almost incomprehensible to the untrained eye. To make these logs more accessible to researchers, they need to be presented in a way that captures only the relevant information, and conveys the researcher's interpretation of the data in a format that is easy to read and preferably familiar to their peers. This is exactly the strength of the Text Encoding Initiative (TEI), whose guidelines recommend the use of XML tags to both transcribe the text as it is recorded on the document, and to encode the researcher's interpretation of that record in a human and computer readable format.

Within the vast realm of possibilities that the TEI allows for, we will do well to check out the work done by its Work Group on Genetic Editions (part of the TEI's Special Interest Group for Manuscripts) that produced the "Encoding Model for Genetic Editions" (2010) to facilitate the encoding of genetic phenomena. The Workgroup focuses on two main requirements: "the ability to encode features of the document rather than those of the text, and the ability to encode time, sequentiality and writing stages in the transcription" (Dillen 2015. 81). These two requirements make for a perfect starting point for a discussion of the differences between analogue and digital textual genetic material.

First of all, in case of digital writing, the spatial organization of the document no longer contains the majority of the information about the genesis of the text - given that an analogue document is a solid (static, physical) information carrier while the digital document is ephemeral (dynamic, virtual). In analogue documents "the dialectic between a document's physical limitations (as a twodimensional surface of limited size) and the internal structure of its different 
writing zones on that surface often contains important clues in the investigation of the text's writing process" (Dillen 2015. 71). For example, the position of the two text zones in the top margin of the notebook page in Figure 1 (within the black squares) and the cramped position of the word "heeft" might indicate that the text in the right-hand zone was written before the text in the left-hand one. The dynamic visualization environment of a word processor, on the other hand, discards this type of information, since it allows text to be inserted at any given position. In case of keystroke logging, the information about the text's writing process is saved in a separate file outside of the main document.

Secondly, the keystroke logging data offers detailed information about the time and sequentiality of all the activities during writing. The genetic scholar can only hypothesize about the sequence in which the two zones in the top margin of the notebook page were written, and can in no way be entirely certain about the sequence of their writing in relation to the rest of the text. When the writing process is logged, the sequence of the writing of the text can be deduced from the keystroke logging data - effectively eliminating the need for this type of guesswork.

\section{What does the document reveal?}

Since the "Documentary Turn" in the late twentieth century, the document has gained a special position in textual criticism - especially within the genetic orientation (Dillen 2015, 81). For our understanding of the text, and to understand its genesis, the documentary context is regarded as a crucial source of information (Dillen 2015: Pierazzo and Stokes 2011). But for born-digital materials, the spatial organization of the document becomes less substantial in the analysis of the text's genesis, since digital documents are essentially distinct from analogue ones. As Mats Dahlström has noted, digital documents cannot be defined materially. In digital documents, works are constituted "by the pattern of signals and tensions at the binary level of the material carrier" (Dahlström 2000, n.p.). Indeed, the graphical user interface (GUI), like the print layout in MS Word, only creates the illusion of the materiality of digital documents (Van Hulle 2019. 468). Yet, at the same time, as Kirschenbaum notes, "a digital environment is an abstract projection supported and sustained by its capacity to propagate the illusion [...] of immaterial behavior: identification without ambiguity, transmission without loss, repetition without originality" (Kirschenbaum 2008. 11). Indeed, as Katherine Hayles argued in "Translating Media: Why We Should Rethink Textuality", digital documents are always bound to a material carrier, in which "data files, programs that call and process the files, hardware functionalities that interpret or compile the programs, and so on" are required to produce the digital document (Hayles 2003. 274). Still, as Ries reminds us, we have to keep in mind that these digital documents "are not bound to a single physical entity, not even to a single processing system context or display application" (Ries 2018. 397). The everyday use of the term 
"document" also seems to complicate its use in textual scholarship: we "speak of the 'same' digital document when we save 'it' after changing its content, after copying 'it' to a pendrive and 'open it' on a different computer with a different word processor which might display the content in a different way" (Ries 2018. 397). In my comparison with the analogue document, I therefore use the term "document" to refer to each Word file in the material recorded with Inputlog: each writing session creates two documents (Word files with .docx extension) and one XML file with the keystroke information (.idfx extension) ${ }^{11}$ Each Word file represents a different stage of the text (session-version) and can be collated as such to gain a first impression of the development of the text during each session.

At the document level, there are two main differences between analogue source materials and born-digital source materials logged with a keystroke logger: 1) keystroke logging abolishes the distinction between interdocumentary and intradocumentary variation; and 2) the document layout no longer contains the primary information about the genesis of the text.

\subsection{Interdocumentary versus intradocumentary variation}

The first difference arises at the level of intradocumentary and interdocumentary variation. In writing on paper, the document pages bear witness of textual genesis through intradocumentary variation (Schäuble and Gabler 2018, 165). Besides this stratification visible on the page, a large part of the textual development also happens off the page, for example in the rewriting of a text (Schäuble and Gabler 2018, 165). This kind of interdocumentary variation can only be made apparent by means of collation. To account for these differences, Schäuble and Gabler proposed a distinction between textual layers and levels. Textual layers represent the intradocumentary variation (i.e. the revisions made to a single document) while textual levels describe the interdocumentary variation (i.e. the differences between two documents) (Schäuble and Gabler 2018, 169).

Encoding interdocumentary changes causes a number of interpretative problems for the editor. When there is no materialization of the change, rules need to be developed for the encoding of the revision (Schäuble and Gabler 2018, 171). To illustrate this need, Schäuble and Gabler discuss how Virginia Woolf changed the phrase "'my mothers [sic] name' (Woolf MS.A.5.b, n3)" to "'my mothers [sic] laughing nickname' (Woolf TS.A.5.a, 54)" during her transcription of her manuscript into a typescript (Schäuble and Gabler 2018, 171). This change could be encoded in several ways:

It could be encoded as a single substitution of the word "name" with "laughing nickname" or as an addition of the word "laughing" followed by a substitution of "name" with "nickname". If we tokenise on a finer level of granularity than the word, it could even be encoded as a single

11 How to preserve those files is yet another question (see, for example, Kirschenbaum et al. 2010). 
addition of the string "laughing nick" that builds a new compound with the following invariant string "name".

(Schäuble and Gabler 2018, 171)

Each of these solutions provides a correct representation of the typescript, but for the editor it is difficult to decide which encoding models the writing act best (Schäuble and Gabler 2018, 171).

For digital writing processes that are tracked with keystroke logging software, the encoding of the writing act would be less ambiguous, since interdocumentary variation is always preceded by intradocumentary variation - which (in most cases) will be recorded through keystroke logging, and saved in a separate file ${ }^{12}$ When using Inputlog, for example, the author can continue to write in a single document for the duration of their entire writing process, while intermediate versions are simultaneously saved as separate documents in the background. If these are logged consistently and without errors, the keystroke logging data encompasses all intradocumentary variation, which in turn provides the information about the interdocumentary variation; in this case, the difference between the Word documents saved at the beginning and the end of a writing session can be visualized by means of collation. An example from Bogaert's writing process may help to clarify how this would work.

A collation of the Word documents that were saved at the start and the end of the seventeenth writing session points at an interdocumentary variant. Here, Bogaert changed the sentence "Mijn oude huis?" [My old house?] into "Mijn oude huid?" [My old skin?]. Following the reasoning used by Gabler and Schäuble, this could be encoded as a substitution of "huis" with "huid" or, at an even finer level, as a substitution of "s" with " $d$ " - both options would be feasible. Since this substitution was logged with Inputlog, the question of how to change occurred is no longer an object of speculation. The keystroke logging data details the sequence of how the revision was carried out: Bogaert first pressed the key " $\mathrm{d}$ " and then used the delete key to remove the "s" (see Table 2).

12 The exceptions to this are the writing sessions in which Bogaert inserted fragments of texts, which he had written in Evernote at times when he did not have his laptop at his disposal. Of these fragments, the keystrokes were not recorded. 
Table 2: The replacement of "s" by " $\mathrm{d}$ " in the keystroke data. ${ }^{+}$

\begin{tabular}{ll|l|llllllll}
\hline \#id & Event Type & Output & Pos. & $\begin{array}{c}\text { Doc. } \\
\text { Len. }\end{array}$ & CP & $\begin{array}{c}\text { Start } \\
\text { Time }\end{array}$ & Start Clock & $\begin{array}{c}\text { End } \\
\text { Time }\end{array}$ & End Clock \\
\hline 21 & keyboard & LEFT & 1838 & 4501 & 4501 & 42308 & $00: 00: 42.308$ & 42355 & $00: 00: 42.355$ \\
22 & keyboard & $\mathrm{d}$ & 1838 & 4501 & 4501 & 43228 & $00: 00: 43.228$ & 43306 & $00: 00: 43.306$ \\
23 & keyboard & DELETE & 2285 & 4501 & 4502 & 43369 & $00: 00: 43.369$ & 43431 & $00: 00: 43.431$ \\
24 & replacement & {$[1839: 1840]$} & 2285 & 4501 & 4502 & 43369 & $00: 00: 43.369$ & 43431 & $00: 00: 43.431$ \\
26 & mouse & Movement & 2285 & 4501 & 4502 & 45397 & $00: 00: 45.397$ & 46083 & $00: 00: 46.083$ \\
\hline
\end{tabular}

Table 3: General Analysis of typing "Of is het $\mathrm{m}$ " and deleting " $\mathrm{M}^{\prime}{ }^{+}$

\begin{tabular}{ll|l|lllllll}
\hline \#id & Event Type & Output & Pos. & $\begin{array}{l}\text { Doc. } \\
\text { Len. }\end{array}$ & CP & $\begin{array}{c}\text { Start } \\
\text { Time }\end{array}$ & Start Clock & $\begin{array}{l}\text { End } \\
\text { Time }\end{array}$ & End Clock \\
\hline 2460 & keyboard & O & 1862 & 4573 & 4774 & 1077967 & $00: 17: 57.967$ & 1078014 & $00: 17: 58.014$ \\
2461 & keyboard & $\mathrm{f}$ & 1863 & 4574 & 4775 & 1078295 & $00: 17: 58.295$ & 1078342 & $00: 17: 58.342$ \\
2462 & keyboard & SPACE & 1864 & 4575 & 4776 & 1078498 & $00: 17: 58.498$ & 1078560 & $00: 17: 58.560$ \\
2463 & keyboard & $\mathrm{i}$ & 1865 & 4576 & 4777 & 1078747 & $00: 17: 58.747$ & 1078778 & $00: 17: 58.778$ \\
2464 & keyboard & $\mathrm{s}$ & 1866 & 4577 & 4778 & 1078825 & $00: 17: 58.825$ & 1078903 & $00: 17: 58.903$ \\
2465 & keyboard & SPACE & 1867 & 4578 & 4779 & 1078966 & $00: 17: 58.966$ & 1079028 & $00: 17: 59.028$ \\
2466 & keyboard & $\mathrm{h}$ & 1868 & 4579 & 4780 & 1079184 & $00: 17: 59.184$ & 1079231 & $00: 17: 59.231$ \\
2467 & keyboard & $\mathrm{e}$ & 1869 & 4580 & 4781 & 1079324 & $00: 17: 59.324$ & 1079387 & $00: 17: 59.387$ \\
2468 & keyboard & $\mathrm{t}$ & 1870 & 4581 & 4782 & 1079418 & $00: 17: 59.418$ & 1079465 & $00: 17: 59.465$ \\
2469 & keyboard & SPACE & 1871 & 4582 & 4783 & 1079730 & $00: 17: 59.730$ & 1079777 & $00: 17: 59.777$ \\
2470 & keyboard & $\mathrm{m}$ & 1872 & 4583 & 4784 & 1080666 & $00: 18: 00.666$ & 1080728 & $00: 18: 00.728$ \\
2471 & keyboard & DELETE & 1911 & 4583 & 4785 & 1081243 & $00: 18: 01.243$ & 1081321 & $00: 18: 01.321$ \\
2472 & replacement & {$[1873: 1874]$} & 1911 & 4583 & 4785 & 1081243 & $00: 18: 01.243$ & 1081321 & $00: 18: 01.321$ \\
\hline
\end{tabular}

$+\quad$ Unfortunately, Inputlog occasionally gives the wrong position in Pos., as is the case with the deletions in Table 2 and Table 3 The correct positions are given in Output, respectively [1839:1840] and [1873:1874] (as opposed to the position given in Pos., respectively 2285 and 1911). For a more detailed explanation of what type of data is logged in which of Inputlog's "General Output" columns, see Appendix Bbelow. 


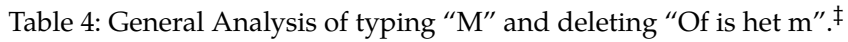

\begin{tabular}{|c|c|c|c|c|c|c|c|c|c|}
\hline$\# i d$ & Event Type & Output & Pos. & $\begin{array}{l}\text { Doc. } \\
\text { Len. }\end{array}$ & $C P$ & $\begin{array}{l}\text { Start } \\
\text { Time }\end{array}$ & Start Clock & $\begin{array}{l}\text { End } \\
\text { Time }\end{array}$ & End Clock \\
\hline 8828 & keyboard & $\mathrm{M}$ & 1834 & 4513 & 5517 & 2647478 & 00:44:07.478 & 2647524 & 00:44:07.524 \\
\hline 8829 & keyboard & DELETE & 1835 & 4513 & 5518 & 2648336 & $00: 44: 08.336$ & 2648336 & $00: 44: 08.336$ \\
\hline 8830 & replacement & [1835:1836] & 1835 & 4513 & 5518 & 2648336 & 00:44:08.336 & 2648336 & $00: 44: 08.336$ \\
\hline 8832 & keyboard & DELETE & 1835 & 4512 & 5518 & 2648835 & 00:44:08.835 & 2648835 & $00: 44: 08.835$ \\
\hline 8833 & replacement & [1835:1836] & 1835 & 4512 & 5518 & 2648835 & $00: 44: 08.835$ & 2648835 & $00: 44: 08.835$ \\
\hline 8835 & keyboard & DELETE & 1835 & 4511 & 5518 & 2648866 & $00: 44: 08.866$ & 2648866 & 00:44:08.866 \\
\hline 8836 & replacement & [1835:1836] & 1835 & 4511 & 5518 & 2648866 & 00:44:08.866 & 2648866 & 00:44:08.866 \\
\hline 8838 & keyboard & DELETE & 1835 & 4510 & 5518 & 2648913 & 00:44:08.913 & 2648913 & 00:44:08.913 \\
\hline 8839 & replacement & [1835:1836] & 1835 & 4510 & 5518 & 2648913 & 00:44:08.913 & 2648913 & 00:44:08.913 \\
\hline 8841 & keyboard & DELETE & 1835 & 4509 & 5518 & 2648944 & $00: 44: 08.944$ & 2648944 & 00:44:08.944 \\
\hline 8842 & replacement & [1835:1836] & 1835 & 4509 & 5518 & 2648944 & $00: 44: 08.944$ & 2648944 & $00: 44: 08.944$ \\
\hline 8844 & keyboard & DELETE & 1835 & 4508 & 5518 & 2648975 & $00: 44: 08.975$ & 2648975 & 00:44:08.975 \\
\hline 8845 & replacement & [1835:1836] & 1835 & 4508 & 5518 & 2648975 & 00:44:08.975 & 2648975 & $00: 44: 08.975$ \\
\hline 8847 & keyboard & DELETE & 1835 & 4507 & 5518 & 2649006 & 00:44:09.006 & 2649006 & 00:44:09.006 \\
\hline 8848 & replacement & [1835:1836] & 1835 & 4507 & 5518 & 2649006 & 00:44:09.006 & 2649006 & 00:44:09.006 \\
\hline 8850 & keyboard & DELETE & 1835 & 4506 & 5518 & 2649053 & $00: 44: 09.053$ & 2649053 & 00:44:09.053 \\
\hline 8851 & replacement & [1835:1836] & 1835 & 4506 & 5518 & 2649053 & 00:44:09.053 & 2649053 & 00:44:09.053 \\
\hline 8853 & keyboard & DELETE & 1835 & 4505 & 5518 & 2649084 & 00:44:09.084 & 2649084 & 00:44:09.084 \\
\hline 8854 & replacement & [1835:1836] & 1835 & 4505 & 5518 & 2649084 & 00:44:09.084 & 2649084 & 00:44:09.084 \\
\hline 8856 & keyboard & DELETE & 1835 & 4504 & 5518 & 2649116 & 00:44:09.116 & 2649131 & 00:44:09.131 \\
\hline 8857 & replacement & [1835:1836] & 1835 & 4504 & 5518 & 2649116 & 00:44:09.116 & 2649131 & 00:44:09.131 \\
\hline 8859 & keyboard & DELETE & 1835 & 4503 & 5518 & 2649553 & $00: 44: 09.553$ & 2649615 & 00:44:09.615 \\
\hline 8860 & replacement & [1835:1836] & 1835 & 4503 & 5518 & 2649553 & $00: 44: 09.553$ & 2649615 & 00:44:09.615 \\
\hline
\end{tabular}

The keystroke data appears to contain even more information about the composition process of this sentence, in that it reveals another modification as well. Somewhat later in the writing process, Bogaert adds the clause "Of is het $\mathrm{m}$ " to the beginning of the sentence and deletes the capital letter " $\mathrm{M}$ " (See Table 3). The sentence now reads: "Of is het mijn oude huid?" [Or is it my old skin?]. But after a while, Bogaert returns to this sentence and changes it back to its previous variant by first adding " $\mathrm{M}$ " and then deleting "Of is het $\mathrm{m}$ " (see Table 4 13 Because this substitution was both performed and undone during the same session, it is not visible in the end document of this particular session (the session-version).

13 Note that Inputlog's "General Analysis" only shows keystrokes and mouse movements. This explains why the deleted text is not visible in the log of Table 4 but only Bogaert's pressing of the delete key. Still, the "General Analysis" does provide information about the position of the deleted characters. The letter " $\mathrm{M}$ " is positioned at 1834 and the subsequent letter at position 1835 is deleted eleven times. This allows us to reconstruct the deleted text. 
When we try to encode this sentence, merging the text with the keystroke data, all the modifications can be put together as follows:

$<$ seg $><$ add $>$ M $<$ / add $><$ del $><$ add $>$ of is het $m</$ add $></$ del $>$
$<$ del $>$ M $</$ del $>$ ijn oude $h u i<$ add $>$ d $</$ add $><$ del $>$ s $</$ del $>$ ? $</$ seg $>$

(Example 1)

The keystroke logging data thus provides more information about interdocumentary revisions than we can extract from analogue material: all interdocumentary variation is captured as intradocumentary variation within the keystroke logging data. When a keystroke logger is used while writing, textual development can no longer occur off the page - or at least: when authors keep their writing process within the confines of their Inputlog enabled computer, and when that process is logged without errors). In Bogaert's case, the records suggest that he occasionally pasted new or revised textual materials into the document that were produced in between explicitly logged writing sessions. This means that for these passages, there is no data available about how the variation came to be.

\subsection{Encoding keystroke logging data instead of the document's layout}

This leads us to the second difference between analogue and born-digital writing processes at the document level, which concerns the appearance of the document page itself. Complex handwritten draft materials often consist of chaotic pages that contain multiple textual fragments that were written at different positions and in different directions on the page. The page of Bogaert's notebook (See Figure 1) shows text written in different colours, in the margins of the page, and between two lines. If we want "to gain insight about the composition, time of revisions, and flow (flux) of the text", we therefore need to carefully consider the physical aspects of the document (its layout, the arrangement of the text on the page, and what this tells us about how the text was written), and to inform that reading of the page with a good understanding of the text (Workgroup on Genetic Editions 2010, §1.3). But when Bogaert uses a word processor, the document remains clean with every modification to the text (see Figure 11): additions are always represented as inline insertions, and deleted text "disappears" from the surface. Logging the process with a keystroke logger that saves these modifications in a separate file prevents them from becoming untraceable. The crucial information about the genesis of the text thus shifts to the keystroke logging data. This calls for a different encoding of the revisions, that focuses on exactly those elements that make a difference in the keystroke logging data.

When the text is composed in a word processor, revisions cannot be specified with the attributes used in encoding analogue material. Instead of indicating the specific writing tool (which may be encoded in orend) or the location in the 


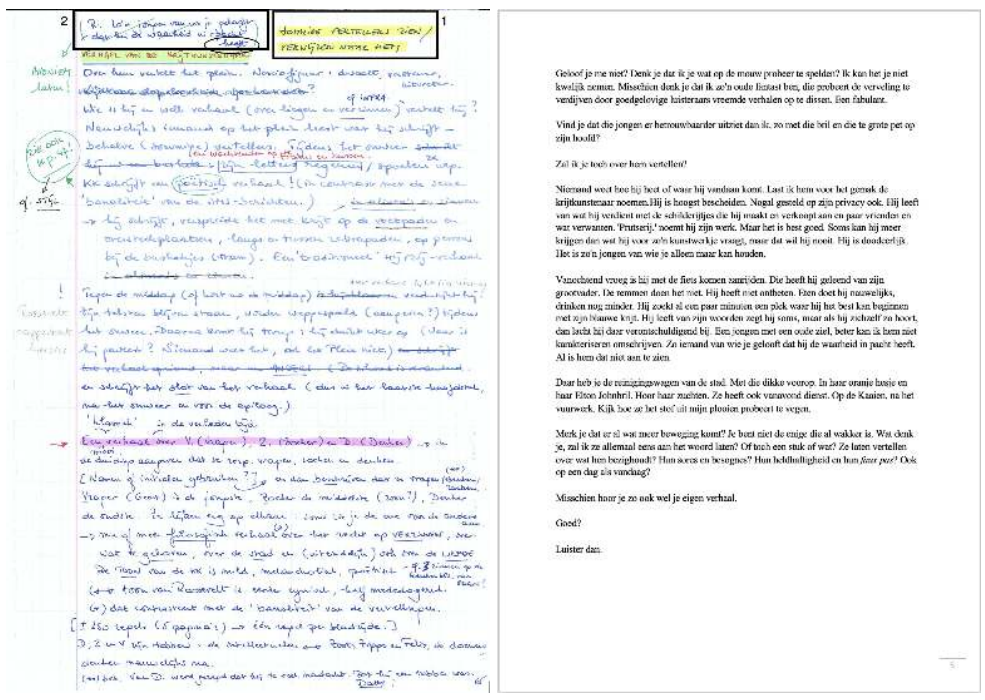

Figure 1: A comparison of Gie Bogaert's analog and digital writing processes. Left: a page in Bogaert's notebook his novel Roosevelt (left). Right: a screenshot of a page in one of Bogeart's MS Word documents for the same novel.

document (which may be encoded in @place), digital revisions (specifically: $<$ add $>$ s and <del>s) can be further specified using their location in the text. These diverging behaviours in the writing of analogue versus digital documents forces us to completely rethink the ontology we use for encoding relative location in our transcriptions. In the following, I therefore propose a list of "revision types" on the basis from Lindgren and Sullivan's so-called "revision taxonomy" (2006a). By using their taxonomy as a starting point, we can encode the relative location of additions and deletions in the attributes of $\langle$ add $>$ and $\langle$ del $1>$ tags in a way that is more relevant to born-digital writing processes (see Tables 5 and 6) 14

The first step in adopting Lindgren and Sullivan's taxonomy is to define revisions according to their relative location in the text, that is "where and when in the writing process revision occurred" (Lindgren and Sullivan 2006b. 42). With regard to this location, the taxonomy distinguishes "pre-contextual" revisions (i.e. "revisions made before an externalised context is completed") from "contextual" revisions ("revisions made within a completed externalised

14 For good measure, the attributes for additions and deletions in witnesses of borndigital writing processes (Table 6 are contrasted to those for analogue writing processes (Table 5). The specific examples that were used to compile these tables are taken specifically from analogue and digital witnesses to Bogaert's writing process, but could be applied more generally. 
context"; see Lindgren and Sullivan 2006a. 159) ${ }^{15}$ These location-based revision types best resemble the use of attributes like @rend or @place, as they are based on the relationship between the keystroke data and the place in the document, rather than purely on the editor's interpretation.

In the encoding of the keystroke data, these revision types may be applied to the textual unit of a sentence ${ }^{16}$ Building upon the taxonomy by Lindgren and Sullivan, the attribute @type="context" can be used to indicate that the revision is a contextual one, that is: a revision made in a previously written sentence. The attribute @type="pre-context", by contrast, may then be used to indicate revisions made before a sentence is completed and so concerns the author's most recently typed characters. Diverging from Lindgren and Sullivan's definition of pre-contextual revisions, pre-contextual deletions can take place at a point in the text with externalized text after the deleted text 17

A large number of revisions in digital writing occur as a result of typographical errors. Within the scope of genetic criticism, such "typos" are not the most meaningful entities because they do not immediately affect the meaning of the text. Within cognitive writing process research, typos are regarded as a revision type that "often blur[s] the picture of the writing session" (Kollberg 1998, 68). Typographical errors are "low-level, and hence less important, types of revision", and filtering them out would therefore allow for a more nuanced analysis of revision (Conijn et al. 2019. 71). But the revision of typographical errors can also break the flow in writing and therefore influence the writing process (Conijn et al. 2019. 72). For this reason, I propose to encode this type of revisions with a separate @type attribute: @type="typo". This allows such errors to be filtered out in visualizations where they are irrelevant, while still allowing us to evaluate their effect on the writing process 18

15 Within cognitive writing process research, the writing process is generally divided into three consecutive components: first the text has to be planned, then these internal ideas have to be translated (externalized) into linguistic forms, and then those forms have to be evaluated and revised where necessary (Lindgren and Sullivan 2006b). While writing, different types of revision occur, and revision is mostly understood as "making any changes at any point in the writing process" (Fitzgerald 1987) 484; Lindgren et al. 2019b 346). Two major categories for such revisions are internal and external revisions. The former encompasses "overall, conceptual revision as well as conscious evaluative revision and revision of pre-text" (Lindgren and Sullivan 2006b 37). The latter are all "visible changes made to the written text" (Lindgren and Sullivan 2006b. 37). Inputlog only logs revisions made in already externalized text; the encoding therefore covers the external revisions.

16 In the proposed encoding scheme, each sentence is encoded with $\mathrm{a}\langle\mathrm{seg}\rangle \mathrm{tag}$.

17 In the taxonomy by Lindgren and Sullivan (2006), one feature of a pre-contextual revision is that there is no externalized text after the place of revision (Lindgren and Sullivan 2006a. 159). As literary writing is often a non-linear process, new context can be created in other places than at the end of the text. In order to be able to distinguish revision within a sentence before this sentence is completed, I also regard these revisions as "pre-contextual".

18 Typing errors can be hard to distinguish from spelling errors. In the encoding of 
The use of a keystroke logger allows for an exact reconstruction of the textual development. This includes the moment a new sentence is produced. Therefore, the production of new sentences can also be incorporated in the encoding (@type="nt"; "new text"), to be able to differentiate between "new" and "old" sentences ${ }^{19}$ Writing is not always a linear process and sentences are not always finished before modifications are performed elsewhere in the text. The author could, for example, move away from the point in the writing where new meaning is produced: the so-called "leading edge" (Lindgren et al. 2019b). In the definition formulated by Lindgren et al., the leading edge is located "typically at the end of the text produced so far, but can also occur at the end of insertions within previously written text where a writer inserts new ideas (not only revises form $)$ " (Lindgren et al. 2019b. 347). Unlike the point of inscription, which comprises "all writers' actions in previously written text as well as at the end of the text produced so far", the leading edge is restricted to the creation of new meaning (Lindgren et al. 2019b, 347). During the production of a sentence the author can decide to leave the sentence produced so far to make a revision elsewhere - in the same sentence or at another segment of the text - after which they return to the end of the sentence they were writing. This would not be an addition, because the sentence is not yet completed. However, the fact that the author moved away from the leading edge is meaningful for the interpretation of the writing process, as it provides information about the steps that were taken to write the sentence. To be able to identify this return to the leading edge, the text can be encoded using <mod>. According to the TEI P5 Guidelines, the $<$ mod > element may be used to represent "any kind of modification identified within a single document" (TEI Consortium 2020. \$11.3.4.1). For the purpose of analysing digital writing processes, it may also be used for the "modification" of unfinished sentences - the continuation of writing the sentence - using the attribute: @type="continue". A transcription with the inclusion of $<$ mod $>$ tries to model the flow of writing.

the typing errors, I therefore used a list of criteria (developed by Stevenson et al. 2006) for distinguishing typing revisions from spelling revisions. According to the checklist developed by Stevenson et al., a revision can be identified as a typing revision, if one or more of the following applies: "a. the pre-revision form does not conform to the orthographic rules of the language; $b$. the pre-revision form involves a letter string which does not conform to a likely pronunciation of the word; $c$. the semantic context indicates that the pre-revision form could not have been intended; $\mathrm{d}$. the same word is written correctly at an earlier point in the text; e. a letter is replaced by an adjacent letter on the keyboard" (Stevenson et al. 2006. 232).

19 Some text segments may also be deleted and added again in a revised form; thereby maintaining a semantic relationship with the previously deleted text. This is not necessarily "new" text and may therefore be given another attribute: @type="rt" ('revised text'). However, the encoding of such revised text adds a new level of interpretation to the transcription. Whereas "new text" is a fairly objective interpretation - as the text is typed into the document for the first time - the classification "revised text" relies on the editor's interpretation and their understanding of the text. 
Table 5: Specifications for additions and deletions in analogue material.

\begin{tabular}{|c|c|c|c|c|}
\hline$\langle$ add $>$ & @hand="\#GB" & $\begin{array}{l}\text { Qrend="\#blueInk" } \\
\text { @rend="\#blackInk" }\end{array}$ & Qtype="\#alternative" & $\begin{array}{l}\text { @place="\#marginleft" } \\
\text { @place="\#supralinear" } \\
\text { @place="\#inline" }\end{array}$ \\
\hline$\langle\operatorname{del}>$ & @hand="\#GB" & Qrend="\#blackInk" & $\begin{array}{l}\text { @type }=" \# \text { crossed Out" } \\
\text { @type }=" \# \text { overwritten" } \\
\text { @type }=" \# \text { instant Correction" } \\
\text { @type }=\text { "\#underlined" }\end{array}$ & \\
\hline
\end{tabular}

Table 6: Specifications for additions and deletions in digital material.

\begin{tabular}{l|l|l|l|l}
\hline$<$ add> & @seq="201308230815" & $\begin{array}{l}\text { @type="context" } \\
\text { @type="pre-context" } \\
\text { @type="typo" } \\
\text { @type="nt" } \\
\text { @type="translocation" }\end{array}$ & @evidence="6514-6556" \\
\hline$<$ del> & @seq="201308230830" & $\begin{array}{l}\text { @type="context" } \\
\text { @type="pre-context" } \\
\text { @type="typo" } \\
\text { @type="translocation" }\end{array}$ & @n="16" & @evidence="6557-6567" \\
\hline <mod> & @seq="201308230840" & @type="continue" & @n="17" & \\
\hline
\end{tabular}

Most of these revision types can be illustrated using the steps taken by Bogaert when he wrote the example sentence from Table 11 ("Soms kan hij meer krijgen dan wat hij voor zo'n kunstwerkje vraagt, maar dat wil hij nooit"). He started by writing "Soms beiden", then moved his cursor between the two words using the left arrow key. There he wrote "krijgt $h$ ". This is a pre-contextual addition, because it takes place before the sentence is finished.

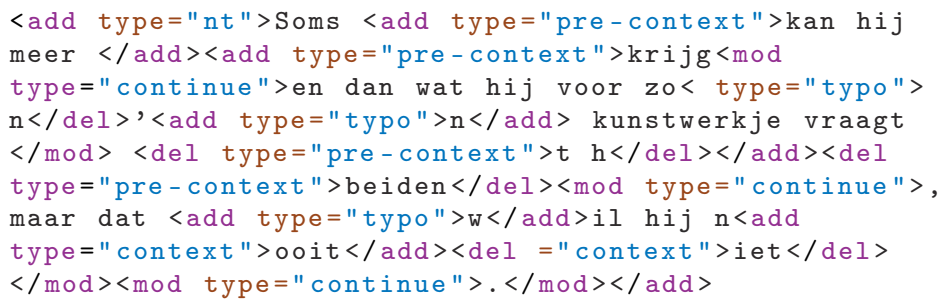

(Example 2)

Bogaert then continued writing with another pre-contextual addition between "Soms" and "krijgt": "kan hij meer". After inserting this fragment, he relocates the cursor between the letter " $g$ " and the letter " $t$ " in the word "krijgt" and continues writing. Bogaert left the leading edge (the point where he created new meaning) to make the pre-contextual additions, but after these 
insertions a new leading edge is created as he continues writing the sentence between the letter " $\mathrm{g}$ " and the letter " $\mathrm{t}$ ". At the new leading edge he writes: "en dan wat hij voor zon' kunstwerkje vraagt"; the screen would now have displayed the sentence as:

Soms kan hij meer krijgen dan wat hij voor zon' kunstwerkje vraagtt hbeiden.

The new leading edge was not positioned at the end of the unfinished sentence, but after the letter $g$ in the word "krijgt". It was thus followed by "t hbeiden".

Bogaert then corrects the typo made in the production "zon," (the apostrophe was incorrectly positioned) after which he eventually deletes the bulk of unused characters at the end of the sentence. These are all pre-contextual deletions; the sentence is still not finished. Now the leading edge is positioned at the end of the sentence, where Bogaert continues writing: " , maar dat il hij niet". After correcting the typo with an addition - he missed the letter " $w$ " in writing "wil" - he types the full stop. This marks the moment the writing of the sentence is finished. Somewhat later in the session, Bogaert returns to the sentence to make a contextual revision. He substitutes "niet" with "nooit" by adding "ooit" and deleting "iet". The writing process of this sentence illustrates the complexity of digital writing, but also demonstrates that the proposed encoding succeeds in capturing every step in the process ${ }^{20}$ Still, this encoding misses an important aspect of the writing process: time.

\section{Specific encoding of time}

Inputlog logs every keystroke and mouse movement in combination with a timestamp. Unlike analogue writing processes, the keystroke logging data allows us to incorporate the specific time of writing into the encoding. Through this temporal aspect, the writer can - so to speak — be followed through the text. Lindgren and Sullivan mention this aspect of keystroke logging too when they argue that the location of revisions

shows how the writers move their points of focus during text composition; this can be viewed as the route writers take through their texts. The actions writers perform during composition can, for example, hint at the writers' developing ideas and associated shifts in text focus.

(Lindgren and Sullivan 2006b 39)

Incorporating the recorded time of the revision into the encoding thus offers a

20 Bogaert explained in conversation that, when writing in the Word document, he focuses primarily on finding the right words. For him, this is the hardest part of the writing process. The rather complex way in which he types this sentence could reflect this. While doing so, he seems primarily orientated towards its reformulation. However, this also reflects Bogaert's personal typing habits. 
unique opportunity to study the text's genesis at a microscopic level — what I referred to as its "nanogenesis" earlier.

The timestamp enables the genetic scholar to investigate the location at which the author was working before they made a revision at another place in the text, when (and how quickly) revisions were made, and if there were certain revision campaigns. To analyse this, the editor may encode the timestamp for each addition and deletion and every other event worth mentioning, by using the @seq attribute (e.g. @seq="yyyymmddhhmmss"). The editor can choose to incorporate the dates of the writing sessions, so as to visualize the chronology of the writing process, not only within a single session but also across several (or all) sessions. The hours, minutes and seconds indicate the time after the start of the session added to the time the session is started ${ }^{21}$ As such, this notation provides the exact time the textual input took place. The TEI P5 Guidelines propose the attribute @seq (sequence) for assigning "a sequence number related to the order in which the encoded features carrying this attribute are believed to have occurred" (TEI Consortium 2020, §11.3.1.4). In the case of the logged writing processes, the eseq attribute can be very specific as the data provides information about the time the deletions and additions were being made.

The timestamp given in eseq can subsequently be used to number all the changes in @n. Using an XSLT script, the events can be listed chronologically in <listChange> and allocated a number ${ }^{22}$ The on includes the number of appearances of all insertions and deletions, as well as all returns to the leading edge. From a computational perspective, the number in @n provides the same information as is given in @seq: the chronology of the modifications. The benefit, however, is for the (human) reader. In the eventual transcription, the numbers will offer the reader the possibility to see the sequence of the revision in one glance (see section 7). This is one step into making the complexity of the (digital) writing process more easily analysable for the reader. The example below shows the encoding of the same sentence discussed above, with the inclusion of the time and the order of appearance, starting from 27.

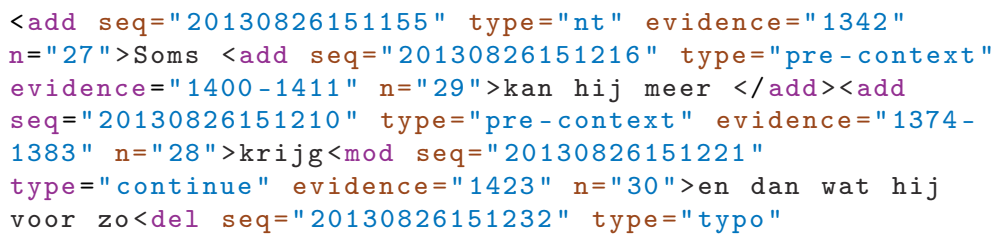

21 The time is derived from the "StartClock" in the "General Analysis" of Inputlog, which is added to the start time of the session in question. In order to be able to retrieve the event in keystroke data, the unique ID of each event in the keystroke data needs to be included in @evidence. As the time of every keystroke is given, the editor needs to make a decision as to which time to incorporate in the encoding. For a genetic analysis, the time of an event's first keystroke may be the most fitting option; for example, when the first key is pressed to start production of a new sentence.

22 I would like to thank Vincent Neyt for writing the XSLT script for this purpose. 


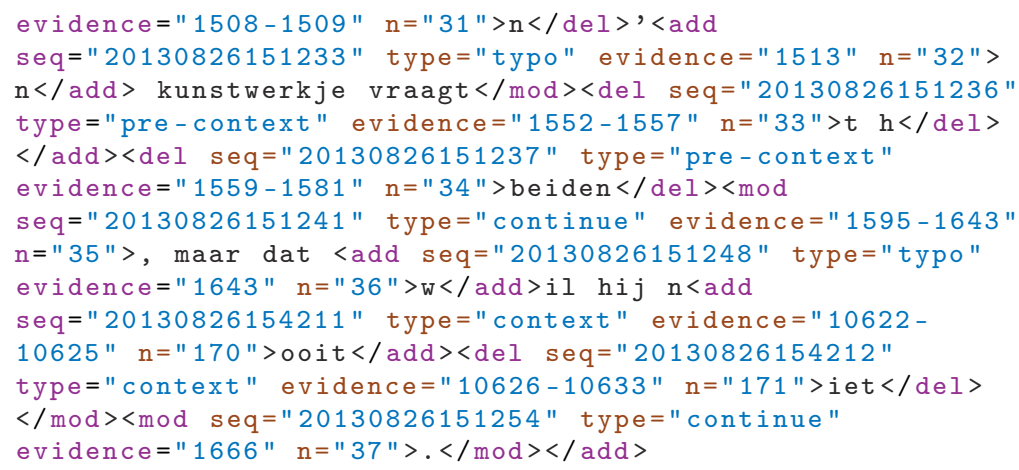

(Example 3)

The number gives the exact order in which the modifications were carried out while keeping editorial interference to a minimum. This contrasts with analogue sources, where the complexity of documentary evidence turns the numbering of revisions into a highly interpretative act resulting only in speculative readings (Dillen 2015, 90). By comparison, the keystroke data allows for a detailed reconstruction not only of the revisions made at sentence level, but those at complete-text level as well. If the author first made a revision to a sentence in the middle of the text and then another in a sentence at the top of the text, this movement through the text can be reconstructed, and also - crucially referenced in analyses of the writing process 23

\section{Peculiarities of digital writing}

In the encoding of the keystroke logging data, the way the text is typed is taken into account. This way, we can distinguish between different typing styles. In this respect, at least two characteristics in digital writing become apparent: 1) the recycling of words and characters, and 2) the different ways of performing a deletion. These characteristics may guide editors in the decisions they make in the encoding of born-digital writing processes.

\subsection{Recycling}

Although the act of deleting is effectively free of cost in a word processor (Sullivan 2013, 256), authors might recycle words and characters in rewriting their texts. This characteristic is also noted by Py Kollberg in her study of digital revisions (1998). She discusses how a writer in her corpus keeps the " $t$ " in substituting "there" for "it":

23 The transcriptions below (see Figure 2 and Figure 4 and the discussion thereof, provide an example of how the numbers in @n can be used to quote specific revisions. 
Probably in order to minimize the effort to make this change, the writer keeps the $t$ in $i t$, and uses it in the new word there. Two elementary character level revisions performed at different positions are the result, but the effect of both revisions is at the word level (and the words are at the same position). Many writers would have deleted the whole word in this situation.

(Kollberg 1998, 78; emphasis in original)

Kollberg concludes that people develop personal habits in their use of the word processor; each writer has their "own personal set of organization of operations" and is used to performing "certain actions in certain ways" (Kollberg 1998 78). Not unlike handwriting, typing styles contain a "fingerprint" of the writer (Lindgren et al. 2019a, 5) ${ }^{24}$ Because genetic criticism is interested in the author's way of working, the way in which they make use of the word processor also needs to be apparent in the transcription.

As for Bogaert's way of typing, his recycling of words is very prominent. Indeed, it is already present in the sample sentence discussed above (see Examples 2 and 3). Here, Bogaert added the clause "en dan wat hij voor zon' kunstwerkje vraagt" between "krijg" and the letter " $t$ " of the word "krijgt". As such, he recycles the word part "krijg", re-using it in the word "krijgen". This re-use can be detected at the word level as well, as Bogaert kept the letter " $n$ " in the substitution of "niet" with "nooit". This is quite characteristic of Bogaert; as Kollberg remarked in a similar situation quoted above, many others would have deleted the entire word.

This recycling of words and characters makes transcription of the writing process a complex matter, as it makes the concise representation of the flow of writing more challenging. This characteristic therefore highlights the importance of encoding the returns to the leading edge with a different tag. In the genetic transcription (Figure 2), it is possible to reconstruct that "en dat wat hij voor zo'n kunstwerkje vraagt" (n30) was written between "krijg" (n28/1) and " $\mathrm{t}$ " " (n28/2) while taking into account that this is not a regular addition, but the writing of the sentence itself. In this visualization, the process of the writing is emphasized and the singularity of Bogaert's writing accentuated. Hence, it is important to encode the separate steps in the writing process in order to be able to reconstruct the flow of writing.

24 This also depends on the computer or laptop used; the keyboards used in a desktop PC set-up are more likely to incite use of the delete key, which is not available as a single button on many laptop keyboard layouts — see also section 6.2 


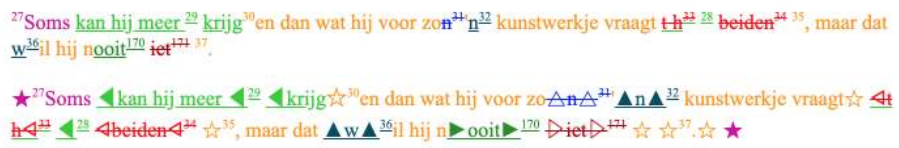

Figure 2: Transcription of a paragraph in session 30, showing all the different modifications. For a legend of the colours and symbols used in this transcription, see Table 7 in Appendix Abelow.

\subsection{Deletions}

Another way in which typing styles become apparent is the usage of the keyboard in making a deletion. As Kollberg notes, a delete operation can be performed in two directions: forwards and backwards (Kollberg 1998, 29). A forward deletion removes characters to the right of the cursor, a backward deletion those to its left (Kollberg 1998, 29). A forward deletion may be carried out by using the delete key or by selecting the characters to the right of the cursor and pressing the backspace key. Using only the backspace key performs a backward deletion. The way the writer uses the keyboard in performing revision affects the encoding of the revision.

When a writer uses the backspace key to delete characters in a substitution - a backward deletion - the deleted word will usually appear in front of the inserted word. If the author uses the backspace key to delete words during the production of a sentence, the cursor is continuously positioned at the end of the leading edge. During production of the clause in Example 4 "de sheerne khoran kan worden gebracht' [the sheerne khoran can be brought], Bogaert changed the simple past tense verb "kon" into the simple present tense "kan". After writing "kon", he deleted "on" and then continued writing by typing "an":

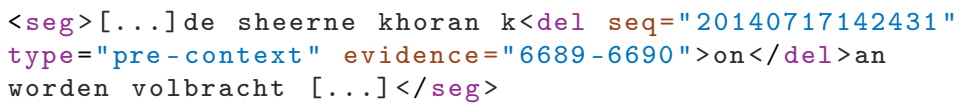

(Example 4)

This pre-contextual deletion can be considered as the digital equivalent of currente calamo deletions in analogue material, which "usually characterize writing produced by an author in the throes of composition, with corrections or revisions made immediately rather than later" (Beal 2011, 104). The linearity of the pre-contextual deletions and the production of the sentence facilitate the readability of the encoding.

The author may also use the delete key to remove a part of the text - a forward deletion. Bogaert prefers this technique: when he makes a substitution, he writes the addition prior to the deletion so that the new word appears to the left of the 
older one - in the substitution of "niet" with "nooit", for instance, the writing of "ooit" preceded the deletion of "iet". The addition therefore appears before the deletion in the encoding. In the encoding of analogue material, however, Elli Bleeker notes that a deletion is normally located

before [i.e. "to the left of"] an addition in a transcription (regardless of the actual positioning of these elements [on the document]), simply because - in the western world - we read a transcription from left to right and we usually assume that a word is first deleted and then replaced.

(Bleeker 2015, 98)

This choice is usually guided by the goal of the transcription of analogue material: to render the text more readable (Bleeker 2015, 98). In the transcription of a digital writing process, the goal is also to reconstruct that process - as this is not visible in the document - and to capture the author's way of working. The additions and deletions are therefore best placed in the position at which they occurred: the way the deletions are performed dictates the decisions made in the encoding.

\section{Interpretation, selection and argumentation}

The proposed encoding produces a transcription of the keystroke logging data in order to provide data output suitable for a genetic analysis. Specifically, it allows for the examination of revisions and new text production, their sequences and their effect on the text. This transcription alone is not sufficient to create a digital genetic edition, but it provides a sound basis for the visualization of the writing process. Moreover, the act of encoding the keystroke logging data does coincide with the encoding practice for analogue material in that, here too, "relatively simple text encoding forces us to make editorial decisions" (Bleeker 2015, 112). In the case of keystroke logged writing processes, the need for abstraction (and therefore interpretation) of the recorded material only increases, because there is so much additional information available to the editor. As the examples above demonstrate, simply converting the writing actions that are recorded in the logging data to their editorial representations already implies making a series of editorial choices, such as selecting the data and deciding where the encoded insertions and deletions should be located in the transcription. While the keystroke logging data serves to make more objective observations about the sequence of the writing, it also forces the editor to make their interpretation of the material even more explicit.

The transcription of the keystroke logging data tries to be as objective as possible. In its proposal to complement a text-oriented approach with a documentoriented one, the TEI Ms SIG refers to the opposition in German editorial theory - as coined by Hans Zeller - between the "Befund" and the "Deutung". Respectively, these refer to "what is there in the source document, the record" (Befund), and "the interpretation of this phenomenon" (Deutung) (TEI Consortium 2020. 
$\S 1.1)$. The Workgroup notes that one cannot talk about the record without any interpretation (especially not in the realm of genetic criticism) but does make a distinction between different levels of interpretation:

there is an obvious difference between the interpretation that some trace of ink is indeed a specific letter and the assumption that a change in one line of a manuscript must have been made at the same time as a change in another line because their effects are textually related.

(TEI Consortium 2020 §1.1)

The Workgroup therefore proposes making a distinction between the interpretation of "what's there" (document/fact) and "how does it relate" (text/interpretation) (TEI Consortium 2020, \$1.1). A similar distinction is made in research into cognitive writing process, when it differentiates between what are called elementary revisions, and interpreted revisions. According to Kollberg, an elementary revision is a single deletion or insertion, and the analysis of such elementary revisions is therefore based only on "the writer's overt action in manipulating the text, with a minimum of interpretation of how revisions may be related according to the writer's intentions" (Kollberg 1998, 16). Interpreted revisions, on the other hand, are revisions which are analysed at a higher level. For example, if "two or more elementary revisions that are seemingly united by the same goal may be combined and interpreted by the researcher as a unit" (Kollberg 1998, 17).

Following that logic, the proposed encoding therefore focuses solely on the elementary revisions. For example, the distinction between contextual and precontextual revisions rests only on the author's actions as they are recorded in the keystroke logging data. When a revision is made during the production of a sentence (before the author presses the full stop), it is marked as a pre-contextual revision. When the revision is made within a completed sentence (after the full stop is typed), it is marked as a contextual revision. In addition, revisions are encoded according to the way they are performed and the replacement of one word with another is not encoded as a substitution 25 Nevertheless, this can only allow for a certain degree of objectivity, since the selection of the material already involves interpretation (Dillen 2018, 38).

Selection plays a pivotal part in the encoding of the keystroke logging data. Although the transcription sets out to represent the author's movement through the text, many indications of movement have been left out of the encoding. The encoding marks only the textual output, as generated by the keyboard, consisting of characters and punctuation marks. As such, it omits the keyboard events "UP", "DOWN", "LEFT" and "RIGHT". The same applies to the mouse movements. In focusing on the textual output, the encoding also ignores data provided about pauses, their locations and the timing of each action. Moreover, as the only time that is encoded in the transcription is the start time of any modification, the time

25 For example, when "niet" is changed to "nooit" by adding "ooit" and deleting "iet", only "ooit" and "iet" are marked with elements. 
between the end of one revision and the start of another is omitted as well. This means that the time between two subsequent revisions cannot be deduced. This does not imply, for instance, that long pauses or other time indications cannot be encoded in the transcription, but rather that such an encoding does not lie within the scope of this particular transcription. The main aim of this transcription is to help the scholar/reader follow the sequence of text production and revisions with a focus on the text and its meaning ${ }^{26}$ By reducing the presentation of other kinds of information, the scholar/reader is less distracted from analysing the text. Still, even with a focus on the textual output, interpretation remains a key factor in the encoding as "the idea of presenting a text in an objective way is problematic and arguably impossible" (Bleeker 2015. 114). This seems even more true when encoding keystroke logging data, as the editor is setting out to reconstruct a state of the text which has never existed in full.

When all the deletions and insertions within a given session are encoded, we arrive at a state of the text that has never actually appeared on the author's computer screen as such, and has therefore never interacted with. This might present us with some issues, such as the question where to encode insertions and deletions when several revisions are located at virtually the same position in the logs (Kollberg 1998, 34). The editor's interpretation is necessary in these instances, especially when the author makes an insertion next to a place in the document where there was a previous deletion. That is the case because when the author inserts text, the text is inserted at the cursor location. But since any previously deleted text remains visible in the encoding, there is no straightforward place to locate the insertion in relation to the previously deleted text (Kollberg 1998, 34). A protocol for such cases could be that when it pertains a single insertion, the insertion should be encoded to the right of the previous deletion - in line with Bleeker's argument for encoding deletions and additions in analogue witnesses. And when it comes to substitutions, the way in which the insertion and deletion were performed could help make the most accurate decision. For example, when new text was inserted first, and the old text forward deleted afterwards, we could transcribe the insertion first (i.e. to the left) and the deletion second (i.e. to the right).

The editor's interpretation also comes to the fore in the transformation of the TEI-XML encoding. Joris van Zundert and Tara Andrews argue that the interface of the digital edition functions as an argument: "Our first observation is that a digital edition's interface is an argument - not just an argument about the text, but also an argument about the "attitude" of the editor, a window into his or her take on methodology and the digital edition itself" (2018, 7). The interface of a digital scholarly edition "is always closely linked to the data model of the underlying data and the editorial principles expressed in this data model", so they function as "an interpretation of knowledge and provide users with

26 Providing another transcription in which the pauses are encoded would indeed be useful, as it would provide information about the fluency of the writing. This may help interpret the sequence of the revisions from a cognitive perspective. 
a more or less "guided" tour through the data and its general presentational setting" (Bleier and Klug 2018. VII). While different transcriptions given below cannot be considered as a fully developed interface, they already function as "an integral part of rhetorical form" since they foreground the textual development (Andrews and Van Zundert 2018, 8). As an example, I shall discuss some possible transcriptions of the paragraph that includes the example sentence I refered to above, with a view to guiding attention towards the dynamics and non-linearity of the writing process - in this case within a single writing session.

The first option is to display a transcription that simply presents a reconstruction of all the textual operations within their textual context. This transcription promotes reading of the text with all the modifications made during this session. The different types of modification are visualized in different colours, which indicate that the writing of this paragraph proceeded in different steps. At a glance, one can see the dynamics that underlie the writing process:

\begin{abstract}
Eagten ik we hem voor het gemak de krijtkunstenar noement Niemand weet hoe hij heet of waar hij vandaan komt. Laat ik hem voor het gemak de krijtkunstenaar noemen. Erg eht veel kan ik niet over hem kwijt. Hij is hoogst bescheiden. Nogal getsteld op zijn privacy ook. Hij leeft van wat hij verdient met de shchilderijtejes die hij maakt en verkoopt aan en paar vrienden en wat verwantenfamileiledent. 'Prutserij,' noemt hij zijn werkhet zelff . Maar het is best welgoed. Soms kan hij meer krijgen dan wat hij voor zon $\underline{n}$ kunstwerkje vraagthbeiden, maar dat wil hij nooitiet. Hij is eok-doodeerlijk. Het $\ddot{i j}$ is zo'n jonegen warvan wie je alleen maar kan houden.
\end{abstract}

Figure 3: Transcription of another paragraph in session 30, displaying all the different modifications.

The transcription can then be modified to show how the text developed during the session. By removing all the added text, this transcription visualizes the text within the paragraph that was already written at the moment Bogaert started this new session:

\title{
Laten we hem voor het gemak de krijtkunstenaar noement. Niemand weet hoe hij heet of waar hij vandaan komt.
}

Figure 4: Transcription of the same paragraph in session 30, displaying the text as it was at the beginning of the session.

Conversely, the deleted text can also be removed. This enables readers to see the state of the text at the end of the session. By providing the option to read the state of the text at the beginning and the end of the session, one is encouraged to focus on how the text developed and on which steps were taken during its writing. This shows that the first and the second sentence were transposed and that Bogaert added eight new sentences 27

27 In fact, Bogeart added nine of them: one of the sentences was then deleted during the same session. 


\begin{abstract}
Niemand weet hoe hij heet of waar hij vandaan komt. Laat ik hem voor het gemak de krijtkunstenaar noemen. Hij is hoogst bescheiden. Nogal gesteld op zijn privacy ook. Hij leeft van wat hij verdient met de schilderijtjes die hij maakt en verkoopt aan en paar vrienden en wat verwanten. 'Prutserij,' noemt hij zij $\underline{\underline{n}}$ werk. Maar het is best goed. Soms kan hij meer krijgen dan wat hij voor zo'n kunstwerkje vraagt, maar dat wil hij nooit. Hij is doodeerlijk. Het is zo'n jongen van wie je alleen maar kan houden.
\end{abstract}

Figure 5: Transcription of a paragraph in session 30, displaying the text at the end of the session.

Next, the sequence of all the modifications can be studied by displaying their numbers in sequential order. The first modifications in this paragraph are the insertions of four new sentences (n14-n17) ${ }^{28}$ the writing of the fourth of these is interrupted by typing errors in "shilderijtejes [sic]" (n18n20; [paintings]), which Bogaert corrects before finishing the sentence with "die hij maakt en verkoopt." (n21; [which he makes and sells]). Hence, if one continues following the sequence of all the writing operations in chronological order, the nanogenesis can be analysed. This shows, for example, that Bogaert wrote the seventh sentence (n22) and then returned to the sixth sentence to insert the clause, with typos, "aan en [sic] paar vieden [sic] en famileileden [sic]" (n23; [to a few friends and family members]). He then immediately substituted "famileileden [sic]" (n25; [family members]) with "verwanten" (n24; [relatives]). The sentences "Maar het is best wel goed" (n99; [But it is pretty good]) and "Het is zo'n jongen van wie je alleen maar kan houden" (n150; [He's the kind of guy you can only love]) were inserted later, which indicates that he did not work continuously on this paragraph but relocated the point of inscription to other locations in the text in the meantime. The order of some revisions might also indicate a relationship between them; the quest to correct typos (n91-n94) and inserting a new sentence after deleting another (n149-n150). The sequence of the modifications shows the continuous shaping and reshaping of the text by Bogaert, a process made possible by the word processor:

\footnotetext{
Eag ${ }^{143} \mathrm{ten}^{144}$ ik ${ }^{+45}$ we ${ }^{+46}$ hem voer het gemak de krijtkunstenaar neemen. ${ }^{+96}$ Niemand weet hoe hij heet of waar hij vandaan komt. Laat ik hem voor het gemak de krijtkunstenaar noemen. ${ }^{197}{ }^{14}$ Exg $^{87}$ eht $^{88}$ veel kan ik niet over hem $\mathrm{kwijt} .{ }^{149}{ }^{15} \mathrm{Hij}$ is hoogst bescheiden. ${ }^{16} \mathrm{Nogal}$ get ${ }^{91} \mathrm{st}{ }^{92}$ eld op zijn privacy ook. ${ }^{17} \mathrm{Hij}$ leeft van wat hij verdient met de $\operatorname{sh}^{18}{ }^{12} \underline{1}^{19}$ ilderijte ${ }^{20}$ jes ${ }^{21}$ die hij maakt en verkoopt aan en paar vr ${ }^{93} \underline{\text { ien }}{ }^{94}$ den en wat

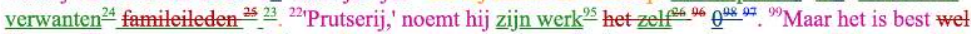

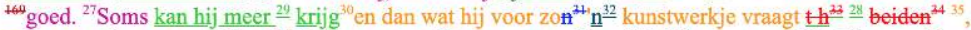
maar dat $\underline{w}^{36}$ il hij nooit ${ }^{170} \mathrm{iet}^{174}{ }^{37} \cdot{ }^{38} \mathrm{Hij}$ is ook ${ }^{108}$ doodeerlijk. ${ }^{150} \mathrm{Het} \underline{t 72}^{172} \mathrm{ij}^{1733}$ is zo'n jone ${ }^{151} \mathrm{ge}^{152} \mathrm{n}$ waar ${ }^{153}$ van wie $\frac{154}{j e}$ alleen maar kan houden.
}

Figure 6: Transcription of a paragraph in session 30, displaying the sequence (numbers) of the modifications. For a legend of the colours and symbols used in this transcription, see Table 7 in Appendix A below.

28 The numbers (e.g., n14) refer to the chronology of each modification made in this paragraph during this logged writing session and coincide with the @n attribute in XML (see also Appendix A. 
Lastly, symbols can be added to the transcription to provide an option for colour-blind users to still be able to distinguish the different modifications (see Appendix A). Adding these symbols can also enhance readability at the borders of the insertions and deletions; for example, by distinguishing the contextual addition "verwanten" within the contextual addition "aan en [sic] paar vienden $[s i c]$ en famileileden $[\mathrm{sic}]$ ":

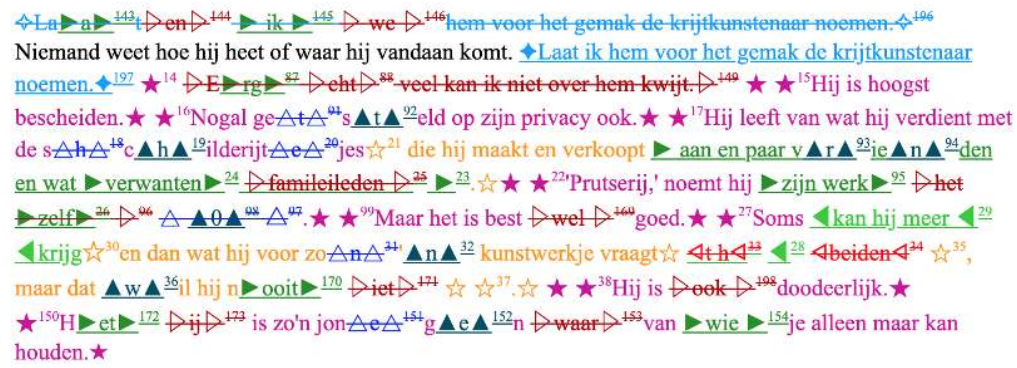

Figure 7: Transcription of a paragraph in session 30, displaying the sequence (numbers) of the modifications and symbols.

Overall, these different transcriptions aim to make the argument that the sequence of the writing operations and the overall development of the text are our main points of attention, and can then be used for further analysis. For example, to examine the effect of the revisions, and how they relate and interact with one another.

\section{New perspectives}

The combination of the Word documents (the session-versions) with the keystroke logging data (the process) serves to uncover a text that had become invisible during the writing process because of the overwriting nature of word processors. The example transcriptions I provided throughout this paper prove that is possible to arrive at a genetic transcription of born-digital works of literature that were composed using a keystroke logger in a way that also makes it possible to represent all the different actions that were performed as the text was written. By adding the time to the revision, the sequentiality of all the revisions can also be reconstructed, which enables a detailed analysis of the way the author moved through the text and how sentences were produced. According to Elena Pierazzo, such a scholarly consideration of time plays a pivotal role in the case of modern autograph drafts and working manuscripts because: 
the stratification of corrections, deletions and additions can give insights into an author's way of working, into the work itself, the evolution of the author's Weltanschauung, the meaning/interpretation of the text.

(Pierazzo 2009. 171)

Compared with analogue text genetic material, the keystroke data encompasses detailed information about the process in which the text was produced. Logging writing processes with a keystroke logger enables an analysis of the textual genesis at a finer granularity: at the level of the work's nanogenesis. Future research will have to indicate whether such a nanogenetic perspective will lead to new perspectives on (the genesis of) a text and the way present-day authors write their texts. In addition, born-digital writing processes alter our notions of "variants" and "versions" (Van Hulle 2019). The transcriptions of the keystroke logging data offer a starting point for reflection on this question and for help in redefining these key concepts. In other words, there are still challenges aplenty for textual scholars in the twenty-first century.

\section{Appendix}

\section{A. Genetic Visualization Notation Legend}

In the transcriptions that were visualized in Figures 2, 3, 4, 5, 6, and 7/ (see pages 26 and $30-32$ above), the different types of modifications are indicated with different colours, and, if preferred, with symbols (see Table 7 below). The numbers in superscript refer to the chronology of each modification made during the logged writing session and coincide with the on attribute in XML. The numbers belong to nearest textual element in the same colour, and the numbers associated with the insertion of new text and the continuation of unfinished sentences are positioned at the beginning of the relevant text segment, while those associated with the revision types are located at its end. Since insertions can be made within insertions, higher numbers can appear within text elements which have been allocated another (lower) number. The same applies to deletions within previous inserted text. If not interrupted by a number and text segment in orange (indicating the continuation of an unfinished sentence) or text and number in red and bright green (respectively pre-contextual deletions and pre-contextual additions) the production of a new sentence was uninterrupted and therefore runs from start to end. 


\begin{tabular}{|c|c|c|}
\hline Symbol & Colour & Indicates \\
\hline$\star$ & medium violet red & newly produced text \\
\hline 约 & orange & returns to the leading edge \\
\hline 4 & bright green & pre-contextual additions \\
\hline$\triangleright$ & dark green & contextual additions \\
\hline$\triangleleft$ & bright red & pre-contextual deletions \\
\hline$\triangleright$ & dark red & contextual deletions \\
\hline$\Delta$ & blue & typo-related deletions \\
\hline$\Delta$ & indigo & typo-related additions \\
\hline$\diamond$ & light blue & relocation of text (deletion) \\
\hline 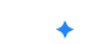 & light blue & relocation of text (addition) \\
\hline
\end{tabular}

Table 7: Legend

\section{B. Inputlog's General Analysis}

Table 8 below shows the General Analysis of the writing process of following sentence in Gie Bogaert's Roosevelt (referenced in Table 1, $\mathrm{p}$ 10, Figure $2, \mathrm{p} 26$. Example 2, p 21, and Example 3, p 23):

Soms kan hij meer krijgen dan wat hij voor zo'n kunstwerkje vraagt, maar dat wil hij nooit.

In the table, the first column (\#id) shows the number of the event (consecutively). In the second column the Event Type indicates the kind of event that was recorded, be that of the type keyboard, mouse, speech, focus, insert or replacement. The next column then shows the event's Output. In case of a keyboard event, this output records the typed letter. The position in the fourth column (Pos.) represents the "cursor position". The fifth column (Doc. Len.) shows the "length of the document" expressed in characters. This differs from the character production represented in the sixth column $(C P)$, which shows all the characters produced during all the writing sessions so far. The Start Time and Start Clock (columns seven and eight) show the time of the "key in" - respectively in milliseconds and in clock time - and the End Time and End Clock (columns nine and ten) of each "key up". The Action Time (Act. Time; column eleven) represents the time between each key in and key up, the Pause Time (column 
twelve) the time between two key ins. The location of the pause is shown in Pause Location (column thirteen).

As such, this table reproduces all the information from Inputlog's logging output, except for three columns: $x, y$, and another Pause Location column (of the same name). In the original output, the $\mathrm{x}$ and $\mathrm{y}$ columns respectively track the location of the mouse on the $x$ and $y$-axes on the screen (Leijten and Van Waes 2013), and are only logged for mouse event types (and therefore remained empty for this writing action). The other Pause Location column was logged a number code for each of the (written out) location types (such as BEFORE WORDS, WITHIN WORDS, etc.) - and therefore carries no additional relevant information. Overall, then, the General Analysis provides information about what was written where and when, and therefore provides all the details needed for a fine-grained reconstruction of the writing process.

Table 8

\begin{tabular}{|c|c|c|c|c|c|c|c|c|c|c|c|c|}
\hline$\# i d$ & Event Type & Output & Pos. & $\begin{array}{l}\text { Doc. } \\
\text { Len. }\end{array}$ & $C P$ & $\begin{array}{l}\text { Start } \\
\text { Time }\end{array}$ & $\begin{array}{l}\text { Start } \\
\text { Clock }\end{array}$ & $\begin{array}{l}\text { End } \\
\text { Time }\end{array}$ & $\begin{array}{l}\text { End } \\
\text { Clock }\end{array}$ & $\begin{array}{l}\text { Act. } \\
\text { Time }\end{array}$ & $\begin{array}{l}\text { Pause } \\
\text { Time }\end{array}$ & Pause Location \\
\hline 1342 & keyboard & $\mathrm{S}$ & 4155 & 6702 & 6737 & 284827 & $00: 04: 44.827$ & 284889 & 00:04:44.889 & 265 & 655 & BEFORE WORDS \\
\hline 1343 & keyboard & o & 4156 & 6703 & 6738 & 285154 & $00: 04: 45.154$ & 285217 & 00:04:45.217 & 63 & 327 & WITHIN WORDS \\
\hline 1344 & keyboard & $\mathrm{m}$ & 4157 & 6704 & 6739 & 285279 & 00:04:45.279 & 285357 & 00:04:45.357 & 78 & 125 & WITHIN WORDS \\
\hline 1345 & keyboard & $\mathrm{s}$ & 4158 & 6705 & 6740 & 285310 & 00:04:45.310 & 285388 & $00: 04: 45.388$ & 78 & 31 & WITHIN WORDS \\
\hline 1346 & keyboard & SPACE & 4159 & 6706 & 6741 & 285498 & 00:04:45.498 & 285560 & $00: 04: 45.560$ & 62 & 188 & AFTER WORDS \\
\hline 1347 & keyboard & $\mathrm{b}$ & 4160 & 6707 & 6742 & 285685 & $00: 04: 45.685$ & 285747 & $00: 04: 45.747$ & 62 & 187 & BEFORE WORDS \\
\hline 1348 & keyboard & e & 4161 & 6708 & 6743 & 285825 & 00:04:45.825 & 285888 & $00: 04: 45.888$ & 63 & 140 & WITHIN WORDS \\
\hline 1349 & keyboard & $\mathrm{i}$ & 4162 & 6709 & 6744 & 285903 & 00:04:45.903 & 285966 & 00:04:45.966 & 63 & 78 & WITHIN WORDS \\
\hline 1350 & keyboard & $\mathrm{d}$ & 4163 & 6710 & 6745 & 286044 & $00: 04: 46.044$ & 286122 & $00: 04: 46.122$ & 78 & 141 & WITHIN WORDS \\
\hline 1351 & keyboard & e & 4164 & 6711 & 6746 & 286231 & $00: 04: 46.231$ & 286278 & $00: 04: 46.278$ & 47 & 187 & WITHIN WORDS \\
\hline 1352 & keyboard & $\mathrm{n}$ & 4165 & 6712 & 6747 & 286356 & 00:04:46.356 & 286418 & 00:04:46.418 & 62 & 125 & WITHIN WORDS \\
\hline 1353 & keyboard & SPACE & 4166 & 6713 & 6748 & 286590 & 00:04:46.590 & 286636 & 00:04:46.636 & 46 & 234 & AFTER WORDS \\
\hline 1368 & keyboard & LEFT & 4160 & 6714 & 6749 & 298368 & 00:04:58.368 & 298399 & 00:04:58.399 & 31 & 11778 & UNKNOWN \\
\hline 1370 & keyboard & RIGHT & 4159 & 6714 & 6749 & 298773 & 00:04:58.773 & 298898 & 00:04:58.898 & 125 & 405 & UNKNOWN \\
\hline 1372 & keyboard & RIGHT & 4160 & 6714 & 6749 & 298976 & 00:04:58.976 & 299085 & 00:04:59.085 & 109 & 203 & UNKNOWN \\
\hline 1374 & keyboard & LEFT & 4161 & 6714 & 6749 & 299319 & 00:04:59.319 & 299429 & 00:04:59.429 & 110 & 343 & UNKNOWN \\
\hline 1376 & keyboard & $\mathrm{k}$ & 4160 & 6714 & 6749 & 300505 & 00:05:00.505 & 300567 & 00:05:00.567 & 62 & 1186 & BEFORE WORDS \\
\hline 1377 & keyboard & $\mathrm{r}$ & 4161 & 6715 & 6750 & 301098 & 00:05:01.098 & 301145 & 00:05:01.145 & 47 & 593 & WITHIN WORDS \\
\hline 1378 & keyboard & i & 4162 & 6716 & 6751 & 301691 & 00:05:01.691 & 301769 & 00:05:01.769 & 78 & 593 & WITHIN WORDS \\
\hline 1379 & keyboard & $j$ & 4163 & 6717 & 6752 & 301800 & 00:05:01.800 & 301878 & 00:05:01.878 & 78 & 109 & WITHIN WORDS \\
\hline 1380 & keyboard & $\mathrm{g}$ & 4164 & 6718 & 6753 & 302096 & 00:05:02.096 & 302143 & 00:05:02.143 & 47 & 296 & WITHIN WORDS \\
\hline 1381 & keyboard & $\mathrm{t}$ & 4165 & 6719 & 6754 & 302237 & 00:05:02.237 & 302299 & 00:05:02.299 & 62 & 141 & WITHIN WORDS \\
\hline 1382 & keyboard & SPACE & 4166 & 6720 & 6755 & 302455 & 00:05:02.455 & 302502 & 00:05:02.502 & 47 & 218 & AFTER WORDS \\
\hline 1383 & keyboard & $\mathrm{h}$ & 4167 & 6721 & 6756 & 302736 & 00:05:02.736 & 302798 & 00:05:02.798 & 62 & 281 & BEFORE WORDS \\
\hline 1384 & keyboard & LEFT & 4168 & 6722 & 6757 & 304483 & $00: 05: 04.483$ & 304545 & 00:05:04.545 & 62 & 1747 & UNKNOWN \\
\hline 1386 & keyboard & LEFT & 4167 & 6722 & 6757 & 304670 & 00:05:04.670 & 304717 & 00:05:04.717 & 47 & 187 & UNKNOWN \\
\hline 1388 & keyboard & LEFT & 4166 & 6722 & 6757 & 304811 & 00:05:04.811 & 304857 & 00:05:04.857 & 46 & 141 & UNKNOWN \\
\hline 1390 & keyboard & LEFT & 4165 & 6722 & 6757 & 304967 & 00:05:04.967 & 305013 & 00:05:05.013 & 46 & 156 & UNKNOWN \\
\hline 1392 & keyboard & LEFT & 4164 & 6722 & 6757 & 305107 & 00:05:05.107 & 305169 & 00:05:05.169 & 62 & 140 & UNKNOWN \\
\hline 1394 & keyboard & LEFT & 4163 & 6722 & 6757 & 305263 & 00:05:05.263 & 305325 & 00:05:05.325 & 62 & 156 & UNKNOWN \\
\hline 1396 & keyboard & LEFT & 4162 & 6722 & 6757 & 305419 & 00:05:05.419 & 305497 & 00:05:05.497 & 78 & 156 & UNKNOWN \\
\hline 1398 & keyboard & LEFT & 4161 & 6722 & 6757 & 305622 & 00:05:05.622 & 305684 & 00:05:05.684 & 62 & 203 & UNKNOWN \\
\hline
\end{tabular}


Table 8: continued

\begin{tabular}{|c|c|c|c|c|c|c|c|c|c|c|c|c|}
\hline \#id & Event Type & Output & Pos. & $\begin{array}{l}\text { Doc. } \\
\text { Len. }\end{array}$ & $C P$ & $\begin{array}{l}\text { Start } \\
\text { Time }\end{array}$ & $\begin{array}{l}\text { Start } \\
\text { Clock }\end{array}$ & $\begin{array}{l}\text { End } \\
\text { Time }\end{array}$ & $\begin{array}{l}\text { End } \\
\text { Clock }\end{array}$ & $\begin{array}{l}\text { Act. } \\
\text { Time }\end{array}$ & $\begin{array}{l}\text { Pause } \\
\text { Time }\end{array}$ & Pause Location \\
\hline 1400 & keyboard & $\mathrm{k}$ & 4160 & 6722 & 6757 & 306480 & 00:05:06.480 & 306527 & 00:05:06.527 & 47 & 858 & BEFORE WORDS \\
\hline 1401 & keyboard & $\mathrm{a}$ & 4161 & 6723 & 6758 & 306558 & 00:05:06.558 & 306651 & 00:05:06.651 & 93 & 78 & WITHIN WORDS \\
\hline 1402 & keyboard & $\mathrm{n}$ & 4162 & 6724 & 6759 & 306667 & 00:05:06.667 & 306729 & 00:05:06.729 & 62 & 109 & WITHIN WORDS \\
\hline 1403 & keyboard & SPACE & 4163 & 6725 & 6760 & 306839 & 00:05:06.839 & 306885 & 00:05:06.885 & 46 & 172 & AFTER WORDS \\
\hline 1404 & keyboard & $\mathrm{h}$ & 4164 & 6726 & 6761 & 307041 & 00:05:07.041 & 307088 & 00:05:07.088 & 47 & 202 & BEFORE WORDS \\
\hline 1405 & keyboard & $\mathrm{i}$ & 4165 & 6727 & 6762 & 307197 & 00:05:07.197 & 307307 & 00:05:07.307 & 110 & 156 & WITHIN WORDS \\
\hline 1406 & keyboard & $j$ & 4166 & 6728 & 6763 & 307291 & 00:05:07.291 & 307369 & 00:05:07.369 & 78 & 94 & WITHIN WORDS \\
\hline 1407 & keyboard & SPACE & 4167 & 6729 & 6764 & 307494 & 00:05:07.494 & 307572 & 00:05:07.572 & 78 & 203 & AFTER WORDS \\
\hline 1408 & keyboard & $\mathrm{m}$ & 4168 & 6730 & 6765 & 307650 & 00:05:07.650 & 307712 & 00:05:07.712 & 62 & 156 & BEFORE WORDS \\
\hline 1409 & keyboard & e & 4169 & 6731 & 6766 & 307790 & 00:05:07.790 & 307868 & 00:05:07.868 & 78 & 140 & WITHIN WORDS \\
\hline 1410 & keyboard & $\mathrm{e}$ & 4170 & 6732 & 6767 & 307931 & 00:05:07.931 & 308009 & 00:05:08.009 & 78 & 141 & WITHIN WORDS \\
\hline 1411 & keyboard & $\mathrm{r}$ & 4171 & 6733 & 6768 & 308009 & 00:05:08.009 & 308055 & 00:05:08.055 & 46 & 78 & WITHIN WORDS \\
\hline 1412 & keyboard & SPACE & 4172 & 6734 & 6769 & 308196 & 00:05:08.196 & 308274 & 00:05:08.274 & 78 & 187 & AFTER WORDS \\
\hline 1413 & keyboard & RIGHT & 4173 & 6735 & 6770 & 309849 & 00:05:09.849 & 309912 & 00:05:09.912 & 63 & 1653 & UNKNOWN \\
\hline 1415 & keyboard & RIGHT & 4174 & 6735 & 6770 & 310037 & 00:05:10.037 & 310068 & 00:05:10.068 & 31 & 188 & UNKNOWN \\
\hline 1417 & keyboard & RIGHT & 4175 & 6735 & 6770 & 310161 & 00:05:10.161 & 310271 & $00: 05: 10.271$ & 110 & 124 & UNKNOWN \\
\hline 1419 & keyboard & RIGHT & 4176 & 6735 & 6770 & 310349 & 00:05:10.349 & 310458 & 00:05:10.458 & 109 & 188 & UNKNOWN \\
\hline 1421 & keyboard & RIGHT & 4177 & 6735 & 6770 & 310707 & 00:05:10.707 & 310785 & 00:05:10.785 & 78 & 358 & UNKNOWN \\
\hline 1423 & keyboard & e & 4178 & 6735 & 6770 & 311409 & 00:05:11.409 & 311487 & 00:05:11.487 & 78 & 702 & BEFORE WORDS \\
\hline 1424 & keyboard & $\mathrm{n}$ & 4179 & 6736 & 6771 & 311550 & 00:05:11.550 & 311597 & 00:05:11.597 & 47 & 141 & WITHIN WORDS \\
\hline 1425 & keyboard & SPACE & 4180 & 6737 & 6772 & 311706 & 00:05:11.706 & 311784 & 00:05:11.784 & 78 & 156 & AFTER WORDS \\
\hline 1426 & keyboard & $\mathrm{d}$ & 4181 & 6738 & 6773 & 311831 & 00:05:11.831 & 311909 & 00:05:11.909 & 78 & 125 & BEFORE WORDS \\
\hline 1427 & keyboard & $\mathrm{a}$ & 4182 & 6739 & 6774 & 311987 & 00:05:11.987 & 312065 & $00: 05: 12.065$ & 78 & 156 & WITHIN WORDS \\
\hline 1428 & keyboard & $\mathrm{n}$ & 4183 & 6740 & 6775 & 312096 & 00:05:12.096 & 312143 & $00: 05: 12.143$ & 47 & 109 & WITHIN WORDS \\
\hline 1429 & keyboard & SPACE & 4184 & 6741 & 6776 & 312252 & $00: 05: 12.252$ & 312330 & 00:05:12.330 & 78 & 156 & AFTER WORDS \\
\hline 1430 & keyboard & $\mathrm{w}$ & 4185 & 6742 & 6777 & 312392 & 00:05:12.392 & 312486 & $00: 05: 12.486$ & 94 & 140 & BEFORE WORDS \\
\hline 1431 & keyboard & a & 4186 & 6743 & 6778 & 312548 & 00:05:12.548 & 312626 & $00: 05: 12.626$ & 78 & 156 & WITHIN WORDS \\
\hline 1432 & keyboard & $t$ & 4187 & 6744 & 6779 & 312626 & $00: 05: 12.626$ & 312689 & 00:05:12.689 & 63 & 78 & WITHIN WORDS \\
\hline 1433 & keyboard & SPACE & 4188 & 6745 & 6780 & 312829 & 00:05:12.829 & 312907 & 00:05:12.907 & 78 & 203 & AFTER WORDS \\
\hline 1434 & keyboard & $\mathrm{h}$ & 4189 & 6746 & 6781 & 313188 & 00:05:13.188 & 313250 & 00:05:13.250 & 62 & 359 & BEFORE WORDS \\
\hline 1435 & keyboard & $\mathrm{i}$ & 4190 & 6747 & 6782 & 313359 & 00:05:13.359 & 313469 & 00:05:13.469 & 110 & 171 & WITHIN WORDS \\
\hline 1436 & keyboard & $\mathrm{j}$ & 4191 & 6748 & 6783 & 313453 & $00: 05: 13.453$ & 313547 & 00:05:13.547 & 94 & 94 & WITHIN WORDS \\
\hline 1437 & keyboard & SPACE & 4192 & 6749 & 6784 & 313687 & 00:05:13.687 & 313765 & $00: 05: 13.765$ & 78 & 234 & AFTER WORDS \\
\hline 1438 & keyboard & $\mathrm{v}$ & 4193 & 6750 & 6785 & 313812 & 00:05:13.812 & 313890 & 00:05:13.890 & 78 & 125 & BEFORE WORDS \\
\hline 1439 & keyboard & o & 4194 & 6751 & 6786 & 313921 & 00:05:13.921 & 313968 & $00: 05: 13.968$ & 47 & 109 & WITHIN WORDS \\
\hline 1440 & keyboard & o & 4195 & 6752 & 6787 & 314046 & 00:05:14.046 & 314108 & 00:05:14.108 & 62 & 125 & WITHIN WORDS \\
\hline 1441 & keyboard & $\mathrm{r}$ & 4196 & 6753 & 6788 & 314155 & 00:05:14.155 & 314217 & $00: 05: 14.217$ & 62 & 109 & WITHIN WORDS \\
\hline 1442 & keyboard & SPACE & 4197 & 6754 & 6789 & 314264 & 00:05:14.264 & 314358 & 00:05:14.358 & 94 & 109 & AFTER WORDS \\
\hline 1443 & keyboard & $\mathrm{z}$ & 4198 & 6755 & 6790 & 314451 & 00:05:14.451 & 314529 & 00:05:14.529 & 78 & 187 & BEFORE WORDS \\
\hline 1444 & keyboard & o & 4199 & 6756 & 6791 & 314592 & 00:05:14.592 & 314654 & 00:05:14.654 & 62 & 141 & WITHIN WORDS \\
\hline 1445 & keyboard & $\mathrm{n}$ & 4200 & 6757 & 6792 & 314810 & 00:05:14.810 & 314857 & 00:05:14.857 & 47 & 218 & WITHIN WORDS \\
\hline 1446 & keyboard & ' & 4201 & 6758 & 6793 & 314919 & 00:05:14.919 & 314966 & $00: 05: 14.966$ & 47 & 109 & WITHIN WORDS \\
\hline 1447 & keyboard & SPACE & 4202 & 6759 & 6794 & 315075 & 00:05:15.075 & 315138 & 00:05:15.138 & 63 & 156 & AFTER WORDS \\
\hline 1448 & keyboard & $\mathrm{k}$ & 4203 & 6760 & 6795 & 315543 & 00:05:15.543 & 315606 & $00: 05: 15.606$ & 63 & 468 & BEFORE WORDS \\
\hline 1449 & keyboard & $\mathrm{u}$ & 4204 & 6761 & 6796 & 315746 & 00:05:15.746 & 315793 & 00:05:15.793 & 47 & 203 & WITHIN WORDS \\
\hline 1450 & keyboard & $\mathrm{n}$ & 4205 & 6762 & 6797 & 315918 & 00:05:15.918 & 315980 & $00: 05: 15.980$ & 62 & 172 & WITHIN WORDS \\
\hline 1451 & keyboard & $\mathrm{s}$ & 4206 & 6763 & 6798 & 316027 & 00:05:16.027 & 316105 & 00:05:16.105 & 78 & 109 & WITHIN WORDS \\
\hline 1452 & keyboard & $\mathrm{t}$ & 4207 & 6764 & 6799 & 316152 & 00:05:16.152 & 316183 & 00:05:16.183 & 31 & 125 & WITHIN WORDS \\
\hline 1453 & keyboard & $\mathrm{w}$ & 4208 & 6765 & 6800 & 316277 & 00:05:16.277 & 316355 & 00:05:16.355 & 78 & 125 & WITHIN WORDS \\
\hline 1454 & keyboard & $\mathrm{e}$ & 4209 & 6766 & 6801 & 316526 & 00:05:16.526 & 316620 & $00: 05: 16.620$ & 94 & 249 & WITHIN WORDS \\
\hline
\end{tabular}


Table 8: continued

\begin{tabular}{|c|c|c|c|c|c|c|c|c|c|c|c|c|}
\hline \#id & Event Type & Output & Pos. & $\begin{array}{l}\text { Doc. } \\
\text { Len. }\end{array}$ & $C P$ & $\begin{array}{l}\text { Start } \\
\text { Time }\end{array}$ & $\begin{array}{l}\text { Start } \\
\text { Clock }\end{array}$ & $\begin{array}{l}\text { End } \\
\text { Time }\end{array}$ & $\begin{array}{l}\text { End } \\
\text { Clock }\end{array}$ & $\begin{array}{l}\text { Act. } \\
\text { Time }\end{array}$ & $\begin{array}{l}\text { Pause } \\
\text { Time }\end{array}$ & Pause Location \\
\hline 1455 & keyboard & $\mathrm{r}$ & 4210 & 6767 & 6802 & 316589 & $00: 05: 16.589$ & 316667 & 00:05:16.667 & 78 & 63 & WITHIN WORDS \\
\hline 1456 & keyboard & $\mathrm{k}$ & 4211 & 6768 & 6803 & 316760 & $00: 05: 16.760$ & 316823 & $00: 05: 16.823$ & 63 & 171 & WITHIN WORDS \\
\hline 1457 & keyboard & $\mathrm{j}$ & 4212 & 6769 & 6804 & 316916 & 00:05:16.916 & 316963 & $00: 05: 16.963$ & 47 & 156 & WITHIN WORDS \\
\hline 1458 & keyboard & $\mathrm{e}$ & 4213 & 6770 & 6805 & 317025 & 00:05:17.025 & 317088 & $00: 05: 17.088$ & 63 & 109 & WITHIN WORDS \\
\hline 1459 & keyboard & SPACE & 4214 & 6771 & 6806 & 317150 & 00:05:17.150 & 317213 & $00: 05: 17.213$ & 63 & 125 & AFTER WORDS \\
\hline 1460 & keyboard & $\mathrm{v}$ & 4215 & 6772 & 6807 & 317369 & 00:05:17.369 & 317415 & 00:05:17.415 & 46 & 219 & BEFORE WORDS \\
\hline 1461 & keyboard & $\mathrm{r}$ & 4216 & 6773 & 6808 & 317540 & 00:05:17.540 & 317587 & 00:05:17.587 & 47 & 171 & WITHIN WORDS \\
\hline 1462 & keyboard & a & 4217 & 6774 & 6809 & 317634 & $00: 05: 17.634$ & 317696 & 00:05:17.696 & 62 & 94 & WITHIN WORDS \\
\hline 1463 & keyboard & a & 4218 & 6775 & 6810 & 317790 & 00:05:17.790 & 317868 & 00:05:17.868 & 78 & 156 & WITHIN WORDS \\
\hline 1464 & keyboard & $\mathrm{g}$ & 4219 & 6776 & 6811 & 317961 & 00:05:17.961 & 318008 & 00:05:18.008 & 47 & 171 & WITHIN WORDS \\
\hline 1465 & keyboard & $\mathrm{t}$ & 4220 & 6777 & 6812 & 318180 & 00:05:18.180 & 318211 & 00:05:18.211 & 31 & 219 & WITHIN WORDS \\
\hline 1504 & keyboard & LEFT & 4202 & 6778 & 6813 & 321581 & $00: 05: 21.581$ & 321596 & 00:05:21.596 & 15 & 3401 & UNKNOWN \\
\hline 1506 & keyboard & LEFT & 4201 & 6778 & 6813 & 321908 & $00: 05: 21.908$ & 321986 & $00: 05: 21.986$ & 78 & 327 & UNKNOWN \\
\hline 1508 & keyboard & DELETE & 4200 & 6777 & 6813 & 322298 & $00: 05: 22.298$ & 322329 & $00: 05: 22.329$ & 31 & 390 & REVISION \\
\hline 1509 & replacement & [4200:4201] & 4200 & 6777 & 6813 & 322298 & $00: 05: 22.298$ & 322329 & $00: 05: 22.329$ & 0 & 0 & CHANGE \\
\hline 1511 & keyboard & RIGHT & 4200 & 6777 & 6813 & 322517 & $00: 05: 22.517$ & 322595 & $00: 05: 22.595$ & 78 & 219 & UNKNOWN \\
\hline 1513 & keyboard & $\mathrm{n}$ & 4201 & 6777 & 6813 & 323546 & $00: 05: 23.546$ & 323609 & 00:05:23.609 & 63 & 1029 & BEFORE WORDS \\
\hline 1546 & keyboard & RIGHT & 4218 & 6778 & 6814 & 324903 & $00: 05: 24.903$ & 324935 & $00: 05: 24.935$ & 32 & 1357 & UNKNOWN \\
\hline 1548 & keyboard & RIGHT & 4219 & 6778 & 6814 & 325231 & $00: 05: 25.231$ & 325309 & 00:05:25.309 & 78 & 328 & UNKNOWN \\
\hline 1550 & keyboard & RIGHT & 4220 & 6778 & 6814 & 325481 & $00: 05: 25.481$ & 325496 & $00: 05: 25.496$ & 15 & 250 & UNKNOWN \\
\hline 1552 & keyboard & DELETE & 4221 & 6777 & 6814 & 325949 & 00:05:25.949 & 325995 & 00:05:25.995 & 46 & 468 & REVISION \\
\hline 1553 & replacement & [4221:4222] & 4221 & 6777 & 6814 & 325949 & $00: 05: 25.949$ & 325995 & 00:05:25.995 & 0 & 0 & CHANGE \\
\hline 1555 & keyboard & SPACE & 4221 & 6777 & 6814 & 326448 & $00: 05: 26.448$ & 326541 & $00: 05: 26.541$ & 93 & 499 & AFTER WORDS \\
\hline 1556 & keyboard & DELETE & 4222 & 6777 & 6815 & 326838 & $00: 05: 26.838$ & 326916 & $00: 05: 26.916$ & 78 & 390 & REVISION \\
\hline 1557 & replacement & [4222:4223] & 4222 & 6777 & 6815 & 326838 & $00: 05: 26.838$ & 326916 & $00: 05: 26.916$ & 0 & 0 & CHANGE \\
\hline 1559 & keyboard & DELETE & 4222 & 6776 & 6815 & 327041 & 00:05:27.041 & 327103 & 00:05:27.103 & 62 & 203 & REVISION \\
\hline 1560 & replacement & {$[4222: 4223]$} & 4222 & 6776 & 6815 & 327041 & 00:05:27.041 & 327103 & 00:05:27.103 & 0 & 0 & CHANGE \\
\hline 1562 & keyboard & DELETE & 4222 & 6775 & 6815 & 327181 & 00:05:27.181 & 327181 & 00:05:27.181 & 0 & 140 & REVISION \\
\hline 1563 & replacement & [4222:4223] & 4222 & 6775 & 6815 & 327181 & 00:05:27.181 & 327181 & 00:05:27.181 & 0 & 0 & CHANGE \\
\hline 1565 & keyboard & DELETE & 4222 & 6774 & 6815 & 327696 & 00:05:27.696 & 327696 & $00: 05: 27.696$ & 0 & 515 & REVISION \\
\hline 1566 & replacement & {$[4222: 4223]$} & 4222 & 6774 & 6815 & 327696 & 00:05:27.696 & 327696 & $00: 05: 27.696$ & 0 & 0 & CHANGE \\
\hline 1568 & keyboard & DELETE & 4222 & 6773 & 6815 & 327727 & $00: 05: 27.727$ & 327727 & $00: 05: 27.727$ & 0 & 31 & REVISION \\
\hline 1569 & replacement & [4222:4223] & 4222 & 6773 & 6815 & 327727 & 00:05:27.727 & 327727 & $00: 05: 27.727$ & 0 & 0 & CHANGE \\
\hline 1571 & keyboard & DELETE & 4222 & 6772 & 6815 & 327758 & $00: 05: 27.758$ & 327758 & $00: 05: 27.758$ & 0 & 31 & REVISION \\
\hline 1572 & replacement & {$[4222: 4223]$} & 4222 & 6772 & 6815 & 327758 & 00:05:27.758 & 327758 & 00:05:27.758 & 0 & 0 & CHANGE \\
\hline 1574 & keyboard & DELETE & 4222 & 6771 & 6815 & 327789 & 00:05:27.789 & 327789 & 00:05:27.789 & 0 & 31 & REVISION \\
\hline 1575 & replacement & {$[4222: 4223]$} & 4222 & 6771 & 6815 & 327789 & 00:05:27.789 & 327789 & 00:05:27.789 & 0 & 0 & CHANGE \\
\hline 1577 & keyboard & DELETE & 4222 & 6770 & 6815 & 327836 & 00:05:27.836 & 327836 & 00:05:27.836 & 0 & 47 & REVISION \\
\hline 1578 & replacement & {$[4222: 4223]$} & 4222 & 6770 & 6815 & 327836 & 00:05:27.836 & 327836 & $00: 05: 27.836$ & 0 & 0 & CHANGE \\
\hline 1580 & keyboard & DELETE & 4222 & 6769 & 6815 & 327867 & $00: 05: 27.867$ & 327899 & 00:05:27.899 & 32 & 31 & REVISION \\
\hline 1581 & replacement & [4222:4223] & 4222 & 6769 & 6815 & 327867 & $00: 05: 27.867$ & 327899 & 00:05:27.899 & 0 & 0 & CHANGE \\
\hline 1583 & keyboard & RETURN & 4222 & 6769 & 6815 & 328476 & $00: 05: 28.476$ & 328569 & $00: 05: 28.569$ & 93 & 609 & BEFORE PARAGRAPHS \\
\hline 1584 & keyboard & RETURN & 4223 & 6770 & 6816 & 328647 & $00: 05: 28.647$ & 328710 & $00: 05: 28.710$ & 63 & 171 & BEFORE WORDS \\
\hline 1585 & keyboard & LEFT & 4224 & 6771 & 6817 & 329147 & $00: 05: 29.147$ & 329240 & $00: 05: 29.240$ & 93 & 500 & UNKNOWN \\
\hline 1587 & keyboard & LEFT & 4223 & 6771 & 6817 & 329334 & $00: 05: 29.334$ & 329396 & 00:05:29.396 & 62 & 187 & UNKNOWN \\
\hline 1589 & keyboard & LEFT & 4222 & 6771 & 6817 & 329490 & 00:05:29.490 & 329584 & $00: 05: 29.584$ & 94 & 156 & UNKNOWN \\
\hline 1591 & keyboard & LEFT & 4221 & 6771 & 6817 & 329693 & $00: 05: 29.693$ & 329771 & 00:05:29.771 & 78 & 203 & UNKNOWN \\
\hline 1593 & keyboard & RIGHT & 4220 & 6771 & 6817 & 330020 & 00:05:30.020 & 330130 & $00: 05: 30.130$ & 110 & 327 & UNKNOWN \\
\hline 1595 & keyboard & , & 4221 & 6771 & 6817 & 330847 & 00:05:30.847 & 330894 & 00:05:30.894 & 47 & 827 & AFTER WORDS \\
\hline 1596 & keyboard & SPACE & 4222 & 6772 & 6818 & 330988 & 00:05:30.988 & 331050 & 00:05:31.050 & 62 & 141 & AFTER WORDS \\
\hline
\end{tabular}


Table 8: continued

\begin{tabular}{|c|c|c|c|c|c|c|c|c|c|c|c|c|}
\hline$\# i d$ & Event Type & Output & Pos. & $\begin{array}{l}\text { Doc. } \\
\text { Len. }\end{array}$ & $C P$ & $\begin{array}{l}\text { Start } \\
\text { Time }\end{array}$ & $\begin{array}{l}\text { Start } \\
\text { Clock }\end{array}$ & $\begin{array}{l}\text { End } \\
\text { Time }\end{array}$ & $\begin{array}{l}\text { End } \\
\text { Clock }\end{array}$ & $\begin{array}{l}\text { Act. } \\
\text { Time }\end{array}$ & $\begin{array}{l}\text { Pause } \\
\text { Time }\end{array}$ & Pause Location \\
\hline 1597 & keyboard & $\mathrm{m}$ & 4223 & 6773 & 6819 & 331175 & 00:05:31.175 & 331237 & $00: 05: 31.237$ & 62 & 187 & BEFORE WORDS \\
\hline 1598 & keyboard & a & 4224 & 6774 & 6820 & 331206 & 00:05:31.206 & 331284 & $00: 05: 31.284$ & 78 & 31 & WITHIN WORDS \\
\hline 1599 & keyboard & a & 4225 & 6775 & 6821 & 331362 & $00: 05: 31.362$ & 331456 & 00:05:31.456 & 94 & 156 & WITHIN WORDS \\
\hline 1600 & keyboard & $\mathrm{r}$ & 4226 & 6776 & 6822 & 331518 & $00: 05: 31.518$ & 331565 & 00:05:31.565 & 47 & 156 & WITHIN WORDS \\
\hline 1601 & keyboard & SPACE & 4227 & 6777 & 6823 & 331736 & 00:05:31.736 & 331799 & 00:05:31.799 & 63 & 218 & AFTER WORDS \\
\hline 1602 & keyboard & d & 4228 & 6778 & 6824 & 331830 & 00:05:31.830 & 331892 & 00:05:31.892 & 62 & 94 & BEFORE WORDS \\
\hline 1603 & keyboard & a & 4229 & 6779 & 6825 & 331986 & 00:05:31.986 & 332064 & 00:05:32.064 & 78 & 156 & WITHIN WORDS \\
\hline 1604 & keyboard & $\mathrm{t}$ & 4230 & 6780 & 6826 & 332111 & 00:05:32.111 & 332142 & $00: 05: 32.142$ & 31 & 125 & WITHIN WORDS \\
\hline 1605 & keyboard & SPACE & 4231 & 6781 & 6827 & 332282 & $00: 05: 32.282$ & 332345 & 00:05:32.345 & 63 & 171 & AFTER WORDS \\
\hline 1606 & keyboard & $\mathrm{i}$ & 4232 & 6782 & 6828 & 332579 & 00:05:32.579 & 332626 & $00: 05: 32.626$ & 47 & 297 & BEFORE WORDS \\
\hline 1607 & keyboard & 1 & 4233 & 6783 & 6829 & 332688 & $00: 05: 32.688$ & 332766 & $00: 05: 32.766$ & 78 & 109 & WITHIN WORDS \\
\hline 1608 & keyboard & SPACE & 4234 & 6784 & 6830 & 332906 & 00:05:32.906 & 332938 & 00:05:32.938 & 32 & 218 & AFTER WORDS \\
\hline 1609 & keyboard & $\mathrm{h}$ & 4235 & 6785 & 6831 & 333203 & 00:05:33.203 & 333250 & $00: 05: 33.250$ & 47 & 297 & BEFORE WORDS \\
\hline 1610 & keyboard & $\mathrm{i}$ & 4236 & 6786 & 6832 & 333374 & $00: 05: 33.374$ & 333515 & 00:05:33.515 & 141 & 171 & WITHIN WORDS \\
\hline 1611 & keyboard & $\mathrm{j}$ & 4237 & 6787 & 6833 & 333484 & 00:05:33.484 & 333577 & 00:05:33.577 & 93 & 110 & WITHIN WORDS \\
\hline 1612 & keyboard & SPACE & 4238 & 6788 & 6834 & 333702 & 00:05:33.702 & 333749 & 00:05:33.749 & 47 & 218 & AFTER WORDS \\
\hline 1613 & keyboard & $\mathrm{n}$ & 4239 & 6789 & 6835 & 333889 & 00:05:33.889 & 333952 & 00:05:33.952 & 63 & 187 & BEFORE WORDS \\
\hline 1614 & keyboard & i & 4240 & 6790 & 6836 & 333998 & 00:05:33.998 & 334076 & 00:05:34.076 & 78 & 109 & WITHIN WORDS \\
\hline 1615 & keyboard & e & 4241 & 6791 & 6837 & 334123 & $00: 05: 34.123$ & 334186 & 00:05:34.186 & 63 & 125 & WITHIN WORDS \\
\hline 1616 & keyboard & $\mathrm{t}$ & 4242 & 6792 & 6838 & 334279 & 00:05:34.279 & 334342 & $00: 05: 34.342$ & 63 & 156 & WITHIN WORDS \\
\hline 1637 & keyboard & LEFT & 4233 & 6793 & 6839 & 336775 & $00: 05: 36.775$ & 336791 & 00:05:36.791 & 16 & 2496 & UNKNOWN \\
\hline 1639 & keyboard & LEFT & 4232 & 6793 & 6839 & 337025 & $00: 05: 37.025$ & 337087 & 00:05:37.087 & 62 & 250 & UNKNOWN \\
\hline 1641 & keyboard & RIGHT & 4231 & 6793 & 6839 & 337399 & 00:05:37.399 & 337508 & 00:05:37.508 & 109 & 374 & UNKNOWN \\
\hline 1643 & keyboard & $\mathrm{w}$ & 4232 & 6793 & 6839 & 338351 & 00:05:38.351 & 338413 & 00:05:38.413 & 62 & 952 & BEFORE WORDS \\
\hline 1644 & keyboard & RIGHT & 4233 & 6794 & 6840 & 341580 & $00: 05: 41.580$ & 341658 & $00: 05: 41.658$ & 78 & 3229 & UNKNOWN \\
\hline 1646 & keyboard & RIGHT & 4234 & 6794 & 6840 & 341767 & 00:05:41.767 & 341767 & $00: 05: 41.767$ & 0 & 187 & UNKNOWN \\
\hline 1648 & keyboard & RIGHT & 4235 & 6794 & 6840 & 342266 & $00: 05: 42.266$ & 342266 & $00: 05: 42.266$ & 0 & 499 & UNKNOWN \\
\hline 1650 & keyboard & RIGHT & 4236 & 6794 & 6840 & 342298 & 00:05:42.298 & 342298 & $00: 05: 42.298$ & 0 & 32 & UNKNOWN \\
\hline 1652 & keyboard & RIGHT & 4237 & 6794 & 6840 & 342344 & 00:05:42.344 & 342344 & 00:05:42.344 & 0 & 46 & UNKNOWN \\
\hline 1654 & keyboard & RIGHT & 4238 & 6794 & 6840 & 342376 & $00: 05: 42.376$ & 342376 & $00: 05: 42.376$ & 0 & 32 & UNKNOWN \\
\hline 1656 & keyboard & RIGHT & 4239 & 6794 & 6840 & 342407 & 00:05:42.407 & 342407 & 00:05:42.407 & 0 & 31 & UNKNOWN \\
\hline 1658 & keyboard & RIGHT & 4240 & 6794 & 6840 & 342438 & $00: 05: 42.438$ & 342438 & $00: 05: 42.438$ & 0 & 31 & UNKNOWN \\
\hline 1660 & keyboard & RIGHT & 4241 & 6794 & 6840 & 342485 & $00: 05: 42.485$ & 342485 & 00:05:42.485 & 0 & 47 & UNKNOWN \\
\hline 1662 & keyboard & RIGHT & 4242 & 6794 & 6840 & 342516 & $00: 05: 42.516$ & 342547 & $00: 05: 42.547$ & 31 & 31 & UNKNOWN \\
\hline 1664 & keyboard & RIGHT & 4243 & 6794 & 6840 & 343000 & $00: 05: 43$ & 343109 & 00:05:43.109 & 109 & 484 & UNKNOWN \\
\hline 1666 & keyboard & . & 4244 & 6794 & 6840 & 344216 & $00: 05: 44.216$ & 344279 & $00: 05: 44.279$ & 63 & 1216 & AFTER WORDS \\
\hline
\end{tabular}

\section{Bibliography}

Andrews, Tara L. and Joris J. Van Zundert, 2018. “What Are You Trying to Say? The Interface as an Integral Element of Argument." In Digital Scholarly Editions as Interfaces, Schriften des Instituts für Dokumentologie und Editorik, volume 12, edited by Roman Bleier, Martina Bürgermeister, Helmut W. Klug, Frederike Neuber, and Gerlinde Schneider, Norderstedt: Books on Demand (BoD), pages 3-34. 
Beal, Peter, 2011. A Dictionary of English Manuscript Terminology: 1450-2000. Oxford: Oxford University Press.

Biasi, Pierre-Marc de, 1996. "What is a Literary Draft? Toward a Functional Typology of Genetic Documentation." Yale French Studies 89, pages 26-58. doi: https://doi.org/10.2307/2930337.

Bleeker, Elli, 2015. “The Future of the Digital Scholarly Editor. Interpretation, Subjectivity and Presence?" Manuscrítica. Revista de crítica genética 28, pages 112-22.

Bleier, Roman and Helmut W. Klug, 2018. "Discussing Interfaces in Digital Scholarly Editing." In Digital Scholarly Editions as Interfaces, Schriften des Instituts für Dokumentologie und Editorik, volume 12, edited by Roman Bleier, Martina Bürgermeister, Helmut W. Klug, Frederike Neuber, and Gerlinde Schneider, Norderstedt: Books on Demand (BoD), pages V-XV.

BOGAERT, GIE, January 2013. “Gie Bogaert over zijn bijzondere manier van schrijven." Available from: https://youtu.be/EhRFiw-RZOY (Accessed: 2020-07-09).

- 2016. Roosevelt. Amsterdam: De Bezige Bij.

Burnard, Lou, 2014. What is the Text Encoding Initiative? How to Add Intelligent Markup to Digital Resources. New Edition [online]. Marseille: OpenEdition Press. doi: https://doi.org/10.4000/books.oep.426

Buschenhenke, Floor, 2016. “Het literaire werk anno 2016. Digitale schrijfprocessen vastleggen en analyseren." Vooys 34(4), pages 8-20.

Conijn, Rianne, Menno van ZaAnen, Mariëlle Leijten, and Luuk Van Waes, 2019. "How to Typo? Building a Process-Based Model of Typographic Error Revisions." The Journal of Writing Analytics 3, pages 69-95.

Crombez, Thomas and Edith Cassiers, 2017. "Postdramatic methods of adaptation in the age of digital collaborative writing." Digital Scholarship in the Humanities 23(1), pages 17-35. doi: https://doi.org/10.1093/llc/fqv054.

DAhlström, Mats, 2000. “Drowning by Versions." Human IT 4(4). Available from: https://humanit.hb.se/article/view/174/187 (Accessed: 2021-06-30).

Dillen, Wout, 2015. Digital Scholarly Editing for the Genetic Orientation: The Making of a Genetic Edition of Samuel Beckett's Works. DPhil, University of Antwerp, Antwerpen. 
— 2018. "The Editor in the Interface: Guiding the User through Texts and Images." In Digital Scholarly Editions as Interfaces, Schriften des Instituts für Dokumentologie und Editorik, volume 12, edited by Roman Bleier, Martina Bürgermeister, Helmut W. Klug, Frederike Neuber, and Gerlinde Schneider, Norderstedt: Books on Demand (BoD), pages 35-59.

Fitzgerald, J., 1987. "Research on revision in writing." Review of Educational Research 57(4), pages 481-506. doi: https://doi.org/10.2307/1170433

Gooding, Paul, Jos Smith, and Justine Mann, 2019. “The forensic imagination: interdisciplinary approaches to tracing creativity in writers' born-digital archives." Archives and Manuscripts 47(3), pages 374-90. doi: https://doi.org/10.1080/01576895.2019.1608837

Hayles, N. Katherine, 2003. “Translating Media: Why We Should Rethink Textuality." Yale Journal of Criticism 16(2), pages 263-90. doi: https://doi.org/10.1353/yale.2003.0018

Kirschenbaum, Matthew G., 2008. Mechanisms: New Media and the Forensic Imagination. Cambridge (MA): MIT University Press.

- 2016. Track Changes: A Literary History of Word Processing. Cambridge (MA): Harvard University Press.

Kirschenbaum, Matthew G., Richard Ovenden, and Gabriela Redwine, 2010. "Digital Forensics and Born-Digital Content in Cultural Heritage Collections." Technical report, Council on Library and Information Resources, Arlington (TX).

Kirschenbaum, Matthew G. and Doug Reside, 2013. “Tracking the Changes: Textual Scholarship and the Challenge of the Born Digital." In The Cambridge Companion to Textual Scholarship, edited by Neil Fraistat and Julia Flanders, Cambridge (MA): Cambridge University Press, pages 257-88.

Kollberg, Py, 1998. S-notation - A computer based method for studying and representing text composition. Lic. thesis, University of Stockholm, Stockholm.

Kollberg, Py and Kerstin S. Eklundh, 2002. "Studying Writers' Revising Patterns with S-Notation Analysis." In Contemporary Tools and Techniques for Studying Writing, Studies in Writing, volume 10, edited by Thierry Olive, C. Michael Levy, and Gert Rijlaarsdam, Dordrecht: Springer, pages 89-104.

Leijten, Mariëlle and Luuk Van Waes, 2013. "Keystroke Logging in Writing Research: Using Inputlog to Analyze and Visualize Writing Processes." Written Communication 30(3), pages 358-92. 
Lindgren, Eva, Yvonne Knopse, and Kirk P.H. Sullivan, 2019a. "Researching Writing with Observational Logging Tools from 2006 to the Present." In Observing Writing. Insights from Keystroke Logging and Handwriting, Studies in Writing, volume 38, edited by Eva Lindgren, Kirk P.H. Sullivan, Raquel Fidalgo, and Thierry Olive, Leiden: Brill, pages 1-29.

Lindgren, Eva and Kirk P.H. Sullivan, 2006a. "Analysing Online Revision." In Computer Keystroke Logging and Writing: Methods and Applications, Studies in Writing, volume 18, edited by Eva Lindgren and Kirk P.H. Sullivan, Oxford: Elsevier, pages 157-88.

, 2006b. "Writing and the Analysis of Revision." In Computer Keystroke Logging and Writing: Methods and Applications, Studies in Writing, volume 18, edited by Eva Lindgren and Kirk P.H. Sullivan, Oxford: Elsevier, pages 31-44.

Lindgren, Eva, Asbjørg Westum, Hanna Outakoski, and Kirk P.H. Sullivan, 2019b. "Revising at the Leading Edge: Shaping Ideas or Clearing up Noise." In Observing Writing. Insights from Keystroke Logging and Handwriting, Studies in Writing, volume 38, edited by Eva Lindgren, Kirk P.H. Sullivan, Raquel Fidalgo, and Thierry Olive, Leiden: Brill, pages 346-65.

Mara, Miriam O'Kane, 2013. “Nuala O'Faolain: new departures in textual and genetic criticism." Irish Studies Review 21(3), pages 342-52. doi: https://doi.org/10.1080/09670882.2013.808873

Mathijsen, Marita, 2009. "Genetic textual editing: the end of an era." In Was ist Textkritik? zur Geschichte und Relevanz eines Zentralbegriffs der Editionswissenschaft, Beihefte zu Editio, volume Bd. 28, edited by Gertraud Mitterauer, Werner Maria Bauer, and Sabine Hofer, Tübingen: Niemeyer.

Miller, Kristvan S and Kirk P.H. Sullivan, 2006. "Keystroke Logging: An Introduction." In Computer Keystroke Logging and Writing: Methods and Applications, Studies in Writing, volume 18, edited by Eva Lindgren and Kirk P.H. Sullivan, Oxford: Elsevier, pages 1-9.

Pierazzo, Elena, 2009. “Digital Genetic Editions: The Encoding of Time in Manuscript Transcription." In Text Editing, Print and the Digital World, edited by Marilyn Deegan and Kathryn Sutherland, Farnham: Ashgate, pages 169-86.

Pierazzo, Elena and Peter A. Stokes, 2011. "Putting the Text back into Context: A Codicological Approach to Manuscript Transcription." In Codicology and Palaeography in the Digital Age 2, Schriften des Instituts für Dokumentologie und Editorik, volume 3, edited by Franz Fischer, Christiane Fritze, and Georg Vogeler, Norderstedt: Books on Demand (BoD), pages 397-429.

Ries, Thorsten, 2017. "Philology and the digital writing process." Genrehybriditeit in de literatuur 9, pages 129-58. 
-, 2018. "The rationale of the born-digital dossier génétique: digital forensics and the writing process with examples from the Thomas Kling Archive." Digital Scholarship in the Humanities 33(2), pages 424-391. doi: https://doi.org/10.1093/llc/fqx049

Schäuble, Joshua and Hans Walter Gabler, 2018. “Encodings and Visualisations of Text Processes across Document Borders." In Digital Scholarly Editions as Interfaces, Schriften des Instituts für Dokumentologie und Editorik, volume 12, edited by Roman Bleier, Martina Bürgermeister, Helmut W. Klug, Frederike Neuber, and Gerlinde Schneider, Norderstedt: Books on Demand (BoD), pages 165-91.

Stevenson, Marie, Rob Schoonen, and Kees de Glopper, 2006. "Revising in two languages: a multi-dimensional comparison of online writing revisions in L1 and FL." Journal of Second Language Writing 15(3), pages 201-33. doi: https://doi.org/10.1016/j.jslw.2006.06.002

Sullivan, Hannah, 2013. The Work of Revision. Cambridge (MA): Harvard University Press.

TAYLOR, C.M., September 2018. “C M Taylor on 'keystroke logging project' with British Library." Available from: https://blogs.bl.uk/english-and-drama/2018/11/c-m-taylor-on-ke ystroke-logging-project-with-british-library.html (Accessed: 2020-06-24).

TEI Consortium, 2020. “TEI P5: Guidelines for Electronic Text Encoding and Interchange." Available from: https://tei-c.org/release/doc/tei-p5-doc/en/Guidelines.pdf (Accessed: 2020-06-24).

Van Hoorenbeeck, Eric, Tom Pauwaert, Luuk Van Waes, and Mariëlle Leijten, 2015. "A generic XML-structure for logging human computer interaction." White Paper. Available from: https://www.inputlog.net/wp-content/up loads/Generic_XML_structure_version-1_3.pdf (Accessed: 2021-06-30).

VAN Hulle, Dirk, 2014. Modern Manuscripts: The Extended Mind and Creative Undoing from Darwin to Beckett and Beyond. London: Bloomsbury.

Rapprochement." Variants 12-13, pages 34-56.

, 2019. "De logica van de tekstversie in digitaal geschreven literatuur." Tijdschrift voor Nederlandse taal en letterkunde/Journal of Dutch Linguistics and Literature 135(4), pages 465-77. 
2021. "Dynamic Facsimiles: Note on the Transcription of Born-Digital Works for Genetic Criticism." Variants 15-16, pages 233-43.

Van Waes, Luuk, Mariëlle Leijten, Åsa Wengelin, and Eva Lindgren, 2011. "Logging Tools to Study Digital Writing Processes." In Past, Present, and Future Contributions of Cognitive Writing Research to Cognitive Psychology, edited by Virginia Wise Berninger, New York (NY): Psychology Press, pages 507-34.

VÁsÁri, Melinda, 2019. "Securing the Literary Evidence. Some Perspectives on Digital Forensics." In Philology in the Making. Analog/Digital Cultures of Scholarly Writing and Reading, edited by Pál Kelemen and Nicolas Pethes, Bielefeld: transcript Verlag, pages 287-309.

Vauthier, Bénédicte, 2016. “Genetic Criticism Put to the Test by Digital Technology: Sounding out the (mainly) Digital Genetic File of El Dorado by Robert Juan-Cantavella." Variants 12-13, pages 163-86.

Wengelin, Åsa, Mark Torrance, Kenneth Holmqvist, Sol Simpson, David Galbraith, Victoria Johansson, and Roger Johansson, 2009. “Combined eye-tracking and keystroke-logging methods for studying cognitive processes in text production." Behavior Research Methods 41(2), pages 337-51. doi: https://doi.org/10.3758/BRM.41.2.337.

Workgroup on Genetic Editions, 2010. "An Encoding Model for Genetic Editions." Available from: https://tei-c.org/Vault/TC/tcw19.html (Accessed: 2020-06-24). 